THAIS HELENA ANDREOLLI DO AMARAL

Materiais para Cimentação de Restaurações Protéticas:

Resposta no Tecido Subcutâneo de Camundongos Isogênicos e na

Polpa de Dentes de Cães.

Dissertação apresentada à Faculdade de Odontologia de Ribeirão Preto da Universidade de São Paulo, para a obtenção do título de Mestre em Odontopediatria.

Orientador: Prof. Dr. Mário Roberto Leonardo

Ribeirão Preto-SP

2007 


\section{FICHA CATALOGRÁFICA}

Amaral, Thais Helena Andreolli do

Materiais para cimentação de restaurações protéticas: Resposta no tecido subcutâneo de camundongos isogênicos e na polpa de dentes de cães. Ribeirão Preto, 2007.

71p. : il. ; $30 \mathrm{~cm}$

Dissertação de Mestrado, apresentada à Faculdade de Odontologia de Ribeirão Preto/USP. Área de concentração: Odontopediatria.

Orientador: Leonardo, Mário Roberto.

1. Proteção pulpar indireta. 2. Materiais para cimentação. 3. Biocompatibilidade 


\section{Materiais para Cimentação de Restaurações Protéticas: Resposta no Tecido Subcutâneo de Camundongos Isogênicos e na Polpa de Dentes de Cães.}

Dissertação apresentada à Faculdade de Odontologia de Ribeirão Preto da Universidade de São Paulo, para a obtenção do título de Mestre em Odontopediatria.

Aprovado em:

Banca Examinadora

Prof. Dr.

Instituição: Assinatura:

Prof. Dr.

Instituição: Assinatura:

Prof. Dr. Instituição: Assinatura: 


\section{DADOS CURRICULARES}

\section{THAIS HELENA ANDREOLLI DO AMARAL}

Nascimento

Filiação

$2000-2003$

2004

2004

2005-2007

2005-2007
21 de junho de 1981 - Ribeirão Preto - SP

José Antonio Alonso do Amaral

Ilda Fany Andreolli

Curso de Graduação

Faculdade de Odontologia de Ribeirão Preto - USP

Curso de Aperfeiçoamento no Atendimento

Odontológico a Bebês Normais e Especiais

Faculdade de Odontologia de Ribeirão Preto - USP

Curso de Aperfeiçoamento em Odontopediatria Associação Paulista de Cirurgiões Dentistas (Ribeirão Preto)

Especialização em Odontopediatria

Associação Odontológica de Ribeirão Preto (AORP)

Curso de Pós-graduação (Mestrado) em Odontologia

Área de Concentração: Odontopediatria

Faculdade de Odontologia de Ribeirão Preto-USP 


\section{OfEREÇO ESTE TRABALHO}

"Força maior deste Universo, que me concedeu o valioso dom da vida, além de uma familia maravilhosa que sempre me manteve inserida num contexto de paz, saúde e amor.

Agradeço, Senhor, pela sua bondade, pela sua graça e pela sua compaixão, que estão sempre presentes, sustentando-me nos momentos mais dificeis." 


\section{DEDICO ESTE TRABALHO,}

Aos meus pais, Ilda Fany Andreolli e José Antonio Alonso do Amaral, que nunca mediram esforços para que eu pudesse crescer e me tornar o que sou hoje. Por todo trabalho e amor dedicados, sem esperar nada em troca, amenizando meus sofrimentos e me ensinando a ser ética e responsável. Obrigada por me ajudarem a trilhar os caminhos da vida, garantindo meus estudos e ajudando a realizar os meus sonhos. Vocês são anjos que conduzem e iluminam a minha vida! Amo muito vocês.

À minha querida avó materna, Anna Cavenaghi Andreolli, e à minha tia, minha segunda mãe, Maria Aparecida Andreolli, por todo apoio e incentivo, não só durante a realização do Mestrado, mas em todos os momentos da minha vida, compartilhando as alegrias, ajudando a aliviar as angústias, e sempre acreditando na minha capacidade. Vocês também são responsáveis por mais esta conquista. Obrigada por tudo. Amo vocês!!

À minha avó paterna, Antonia Baldo Alonso Batista, por me incentivar e apoiar em todos os momentos. Obrigada por sempre acreditar em mim! Espero poder continuar dividindo com você todas as minhas conquistas e realizações. Você permanecerá eternamente em meu coração! Amo você!

Ao meu avô materno, Bento Andreolli (in memorian), e ao meu avô paterno, Benedito Batista do Amaral (in memorian), por todo amor, carinho e dedicação em muitos momentos da minha vida. Deus deve ter tido um motivo muito forte para levá-los tão cedo de nossas vidas. Sempre levarei vocês em meus pensamentos e, principalmente, em meu coração. Amo vocês!

Ao meu irmão, Jose Vitor Sy/vestre do Amaral, que mesmo distante mora no meu coração. Te amo!

Ao meu namorado, Rodrigo Edson Santos Barbosa, pela paciência, incentivo, amor e compreensão durante todo esse tempo que estamos juntos. Além de ser meu grande amor, você é também um exemplo para mim. Admiro sua inteligência, perseverança e responsabilidade em tudo o que faz. Obrigada por ser meu companheiro e por estar perto de mim nos momentos em que mais precisei. Sei que ainda realizaremos muitos sonhos juntos. Te amo muito!

A toda a minha família, tios, tias, primos e primas, pelos laços que nos unem, pelo amor e convivência carinhosa durante toda a minha vida.

"Quem caminha sozinho pode até chegar mais rápido, mas aquele que vai acompanhado, com certeza, vai mais longe!" 


\section{AGRADECIMENTOS ESPECIAIS}

Ao meu orientador, Prof. Dr. Mário Roberto Leonardo, por toda paciência, dedicação e apoio durante a realização do curso de Mestrado. Seus ensinamentos e experiências foram muito valiosos para o meu crescimento profissional. Admiro sua capacidade, inteligência, humildade e disponibilidade em ajudar. Você sempre será para mim um exemplo a ser seguido. Ao senhor, minha eterna gratidão!

À Profa. Dra. Léa Assed Bezerra da Silva, pela valiosa colaboração na realização deste trabalho. Agradeço por ter participado ativamente de todas as etapas. Sua dedicação e amor à pesquisa são admiráveis. Sem sua disponibilidade e paciência eu não teria chegado até aqui. Obrigada por estar sempre pronta a me ajudar. 
Ao Prof. Dr. Paulo Nelson Filho. Professor que admiro desde os tempos da graduação. Você sempre foi um exemplo para mim. Seu amor e dedicação à Odontopediatria são admirāveis. Obrigada pela paciência e boa vontade em me ajudar. De alguma forma você guiou meus passos para que eu pudesse chegar até aqui. Obrigada por tudo!

Ao Prof. Dr. Alberto Consolaro, pela valiosa colaboração no desenvolvimento deste trabalho. Obrigada pela disponibilidade, paciência e atenção. Serei eternamente grata!

À Prof. Dra. Gisele Faria, pela colaboração durante a realização deste trabalho. Agradeço pela amizade, disponibilidade e boa vontade. Obrigada por tudo!

À Prof. Dra. Maria da Conceição Pereira Saraiva, pela disponibilidade e orientação na análise estatistica dos resultados. Obrigada!

Aos colegas Sy/vie Brener e Milton Santamaria Jünior, pela colaboração e disponibilidade. Muito obrigada!

À amiga Andreza Garofalo Izaias, pela colaboração e amizade. Você é uma pessoa encantadora e que, com certeza, se tornou uma amiga muito especial. Obrigada por tudo!

Ao amigo Francisco Wanderley Garcia de Paula e Silva, por todo apoio e ajuda em todos os momentos que precisei. Você é uma pessoa admirā́vel pela sua garra, persistência e dedicação em tudo que faz. Tenho certeza que você se tornará um grande professor e pesquisador. Torço por você! Obrigada por me aconselhar e ajudar nos momentos em que mais precisei. Você é um dos responsáveis por eu ter conseguido chegar até aqui. Obrigada de coração!

Às amigas Carolina de Souza Guerra e Maria Stella Gaspar Gomes Raffaini, por todos os momentos que passamos juntas, tanto na área profissional como pessoal, por todo apoio e incentivo durante a realização do curso de Mestrado. Obrigada por sempre oferecerem o ombro amigo, dividindo as angústias e compartilhando as alegrias. Desejo a vocês muito sucesso e que possamos manter nossa amizade ao longo de toda a vida. Obrigada por tudo. Adoro vocês!

Aos amigos Cristiano Nakạo e Mírian de Cássia Bretas, pela amizade, carinho e atenção. Aprendi que, independente do lugar onde estamos e do tempo que ali permanecemos, sempre existirão pessoas capazes de transformar nossas vidas e deixar marcas que ficarão registradas por toda a nossa existência. Adoro vocês!! 


\section{MEUS AGRADECIMENTOS}

À Faculdade de Odontologia de Ribeirão Preto da Universidade de São Paulo, na pessoa de sua Diretora, Profa. Dra. Marisa Semprinie da Vice-Diretora Profa. Dra. Sada Assed.

À Coordenação do Programa de Pós-Graduação em Odontopediatria da Faculdade de Odontologia de Ribeirão Preto da Universidade de São Paulo, na pessoa da coordenadora Profa. Dra. Léa Assed Bezerra da Silva e do Vice-Coordenador Prof. Dr. Paulo Nelson Filho.

Aos docentes do Departamento de Clínica Infantil, Odontologia Preventiva e Social da Faculdade de Odontologia de Ribeirão Preto-USP, Prof. Dr. Adilson Thomazinho, Profa. Dra. Aldevina Campos de Freitas, Prof. Dr. José Tarcísio Lima Ferreira, Profa. Dra. Kranya Victória Díaz Serrano, Profa. Dra. Léa Assed Bezerra da Silva, Profa. Dra. Sada Assed, Prof. Dr. Mário Roberto Leonardo, Profa. Dra. Maria Bernadete Sasso Stuani, Profa. Dra. Maria Conceição Pereira Saraiva, Profa. Dra. Maria Cristina Borsatto, Profa. Dra. Mírian Aiko Nakane Matsumoto, Profa. Alexandra Mussolino de Queiroz, Prof. Dr. Paulo Nelson Filho pela agradăvel convivência e ensinamentos.

Aos funcionários do Departamento de Clínica Infantil, Odontologia Preventiva e Social da Faculdade de Odontologia de Ribeirão Preto da Universidade de São Paulo, Fătima Aparecida Jacinto Daniel, Marco Antônio dos Santos, Nilva Aparecida Afonso Ruggiero, Rejane Gomes Cavalheiro Mazer, Cleber Barbosa Rita, Vera Ribeiro do Nascimento, José Aparecido Neves do Nascimento e Carmo Euripedes Terra Barreto pela amizade e atenção dispensada.

Aos funcionários do "Centro de Formação de Recursos Humanos Especializados no Atendimento Odontológico de Pacientes Especiais", Benedita Viana Rodrigues, Fătima Rizóli, Nadir Felício e Renata Aparecida Fernandes Rodrigues, pelo carinho e atenção constante.

Ao Marco Antônio dos Santos, por toda ajuda e disponibilidade na realização do processamento histológico.

Ao Edson Luiz Mori, por toda ajuda durante al gumas etapas da realização da metodologia.

À Carolina Paes Torres e Raquel Assed Bezerra da Silva por terem me ajudado em muitos momentos. Obrigada!

À Isabel Cristina Galino Sola e à Regiane Cristina Moi Sacilotto, funcionárias da Seção de Pós-graduação por toda dedicação. 
Às colegas de mestrado Iza Teixeira Alves Peixoto, Cristiane Tomaz Rocha, Jaciara Gomes Miranda Silva, Carolina de Souza Guerra, Christiane Ristum Bagatin Rossi, Maria Stella Gaspar Gomes Raffaini, Regina Aparecida Segato Saiani, Soraya Dibb Sheyer Gonçalves, Patrícia Maria Monteiro e Patrícia Motta Fernandes, pela agradável convivência e amizade.

Ao Júlio César de Matos e Clăudia Regina Côrrea de Matos, pela diagramação e impressão deste trabalho.

À FAPESP (Fundação de Amparo à Pesquisa do Estado de São Paulo), pelo suporte técnico, científico e financeiro fundamentais para a realização deste trabalho.

A todas as pessoas que, de algum modo, contribuiram para a concretização deste trabalho. 
"Os desafios da alma não são fáceis. Mas o crescimento que advém da aceitação desses desafios é sempre compensador. Não aceite viver uma vida medíocre só porque é mais fácil. O mundo, felizmente, será sempre cheio de desconhecidos; de alturas que nunca foram alcançadas; lugares que nunca foram vistos; idéias que nunca foram pensadas; criações que nunca foram criadas. Não é preciso que sejam imensas alturas, nem fantāsticas idéias, nem estupendas criações... Basta que seja um pouco mais que seu limite de agora. Não caia na tentação de aceitar limites confortāiveis onde procurará simplesmente viver do jeito que der e até quando puder.

Se você se esforçar em ampliar os seus limites, um pouco de cada vez, porém sempre mais, sempre se expandindo, descobrirá a verdadeira finalidade da vida e o prazer de vencer o maior dos desafios: o de superar a si mesmo! Descubra seu caminho, pois ninguém mais pode descobri-lo por você. E siga-o, pois só você pode trilhá-lo. Respeite seus sonhos, idéias e sua verdadeira vontade. Nunca, "nunca desista deles, pois são as únicas coisas concretas num mundo de sombras em eternas mutações."

(Autor desconhecido) 


\section{Resumo}

Amaral, THA. Materiais para cimentação de restaurações protéticas: Resposta no tecido subcutâneo de camundongos isogênicos e na polpa de dentes de cães [dissertação]. Ribeirão Preto: Faculdade de Odontologia de Ribeirão Preto da Universidade de São Paulo; 2007.

O objetivo desse trabalho foi avaliar a biocompatibilidade de diferentes agentes cimentantes (Ketac $^{\mathrm{TM}}$ Cem Easy Mix - 3M ESPE e RelyX ${ }^{\mathrm{TM}}$ Unicem - 3M ESPE) microscopicamente, por meio de implantes em tecido conjuntivo subcutâneo de camundongos isogênicos; microscópica e radiograficamente, após aplicação em cavidades profundas, próximas à polpa, em dentes de cães. No estudo em tecido conjuntivo subcutâneo foram utilizados quarenta camundongos isogênicos da linhagem BALB/c divididos em 9 grupos com 3 períodos experimentais: Grupo I: Ketac ${ }^{\mathrm{TM}}$ Cem Easy Mix (7 dias), Grupo II: RelyX ${ }^{\mathrm{TM}}$ Unicem (7 dias), Grupo III: tubo de polietileno vazio (7 dias), Grupo IV: Ketac ${ }^{T M}$ Cem Easy Mix (21 dias) Grupo V: RelyX ${ }^{\mathrm{TM}}$ Unicem (21 dias), Grupo VI: tubo de polietileno vazio (21 dias), Grupo VII: Ketac $^{T M}$ Cem Easy Mix (63 dias), Grupo VIII: RelyX ${ }^{T M}$ Unicem (63 dias), Grupo IX: tubo de polietileno vazio (63 dias). No estudo em dentes de cães foram utilizados quarenta dentes (80 raízes) de 4 cães, distribuídos em 6 grupos: Grupo I: Ketac ${ }^{\mathrm{TM}}$ Cem Easy Mix (7 dias), Grupo II: RelyX ${ }^{\mathrm{TM}}$ Unicem (7 dias), Grupo III: Cimento de óxido de zinco e eugenol (7 dias), Grupo IV: Ketac ${ }^{\mathrm{TM}}$ Cem Easy Mix (70 dias) Grupo V: RelyX ${ }^{\mathrm{TM}}$ Unicem (70 dias), Grupo VI: Cimento de óxido de zinco e eugenol (70 dias). A análise microscópica no tecido conjuntivo subcutâneo foi realizada em microscópio de luz comum, baseada nos seguintes parâmetros: infiltrado inflamatório (celularidade e tipo de célula) e reparo tecidual. $\mathrm{Na}$ análise microscópica em dentes de cães, foi registrada a descrição completa das características da dentina, polpa e tecidos periapicais de acordo com os seguintes aspectos: Presença de polpa normal; Presença de dentina reacional; Presença de ulceração; Pulpite e Presença de necrose pulpar, sendo os resultados submetidos à análise estatística utilizando-se o teste exato de Fisher $(p<0,05)$. A avaliação radiográfica foi realizada por meio de radiografias periapicais obtidas previamente à execução dos atos operatórios e após os períodos experimentais, com relação à integridade da lâmina dura, presença ou ausência de reabsorções radiculares e áreas de rarefação óssea periapical. Os resultados da análise microscópica evidenciaram que, quando empregados sobre a dentina, ambos os cimentos não ocasionaram reações pulpares insatisfatórias. No entanto, quando colocados diretamente sobre o tecido pulpar, desencadearam reação inflamatória intensa, com necrose pulpar e desenvolvimento de reação periapical. No tecido conjuntivo subcutâneo de camundongos, o $\mathrm{Ketac}^{\mathrm{TM}}$ Cem Easymix apresentou resposta inflamatória e fenômenos reacionais intensos em todos os períodos analisados. Já o RelyX ${ }^{\mathrm{TM}}$ Unicem apresentou resposta inflamatória discreta com reparo tecidual nos períodos mais tardios. Podemos concluir que os cimentos RelyX ${ }^{\mathrm{TM}}$ Unicem e $\mathrm{Ketac}^{\mathrm{TM}}$ Cem Easymix apresentaram resultados satisfatórios, quando empregados na dentina de cavidades profundas, sem exposição pulpar. No entanto, quando em contato com o tecido conjuntivo subcutâneo e com o tecido pulpar em microexposições apresentaram resultados insatisfatórios.

Palavras-chave: Proteção pulpar indireta, materiais para cimentação, biocompatibilidade. 


\begin{abstract}
Amaral, THA. Luting materials for prosthetic restorations: Response in the subcutaneous tissue of isogenic mice and dogs' pulp tissue [dissertação]. Ribeirão Preto: Faculdade de Odontologia de Ribeirão Preto da Universidade de São Paulo; 2007.
\end{abstract}

The purpose of this study was to evaluate the biocompatibility of different luting agents (Ketac $^{\mathrm{TM}}$ Cem Easy Mix - 3M ESPE and RelyX ${ }^{\mathrm{TM}}$ Unicem - 3M ESPE), microscopically, by means of implants in the subcutaneous connective tissue of isogenic mice; microscopically and radiographically, after application to deep cavities, close to the pulp, in dogs' teeth. In the study in subcutaneous connective tissue, 40 isogenic BALB/c mice were allocated in 9 groups with 3 experimental periods: Group I: Ketac Cem Easy Mix ${ }^{\circledR}$ (7 days), Group II: RelyX ${ }^{\mathrm{TM}}$ Unicem (7 days), Group III: empty polyethylene tube (7 days), Group IV: Ketac ${ }^{\mathrm{TM}}$ Cem Easy Mix (21 days) Group V: RelyX ${ }^{\mathrm{TM}}$ Unicem (21 days), Group VI: empty polyethylene tube (21 days), Group VII: Ketac ${ }^{\mathrm{TM}}$ Cem Easy Mix (63 days), Group VIII: RelyX ${ }^{\mathrm{TM}}$ Unicem (63 days), Group IX: empty polyethylene tube (63 days). In the study in the pulp tissue of dogs' teeth, 40 teeth (80 roots) of 4 dogs were used and assigned to 6 groups: Group I: Ketac ${ }^{\mathrm{TM}}$ Cem Easy Mix ( 7 days), Group II: RelyX ${ }^{\mathrm{TM}}$ Unicem (7 days), Group III: zinc oxide and eugenol cement (7 days), Group IV: Ketac ${ }^{\mathrm{TM}}$ Cem Easy Mix (70 days) Group V: RelyX ${ }^{\mathrm{TM}}$ Unicem (70 days), Group VI: zinc oxide and eugenol cement (70 days). The microscopic analysis of the subcutaneous connective tissue was performed under standard ligth microscopy, according to the following parameters: presence of inflammatory infiltrate (cellularity and cell type) and tissue repair. In the microscopic analysis in dogs' teeth, a comprehensive description of dentin, pulp and periapical tissue characteristics was undertaken, based on the following aspects: presence of normal pulp; presence of reparative dentin; presence of ulceration; presence of pulpitis; and presence of pulp necrosis. The radiographic evaluation was performed by means of the analysis of periapical radiographs taken before the operative procedures and at the experimental periods, with respect to the integrity of the lamina dura, presence or absence of root resorptions and areas of periapical bone rarefaction. The results of the microscopic analysis demonstrated that, when applied to dentin, both cements did not cause adverse pulp reactions. Nevertheless, when applied directly to the pulp tissue, the luting agents triggered an intense inflammatory response, with pulp necrosis and development of periapical reaction. In the subcutaneous connective tissue of mice, Ketac ${ }^{\mathrm{TM}}$ Cem Easymix induced an inflammatory response and intense reactive phenomena at all analyzed periods. On the other hand, Rely $X^{\mathrm{TM}}$ Unicem induced a discrete inflammatory response with tissue repair at the later periods. It may be concluded that RelyX ${ }^{\mathrm{TM}}$ Unicem and $\mathrm{Ketac}^{\mathrm{TM}}$ Cem Easymix luting agents presented satisfactory results when applied to the dentin of deep cavities without pulp exposure. However, when placed in contact with the subcutaneous connective tissue and pulp tissue in areas of micro-exposures, these materials presented unsatisfactory results.

Key words: Indirect pulp capping, luting materials, biocompatibility. 


\section{SUMÁRIO}

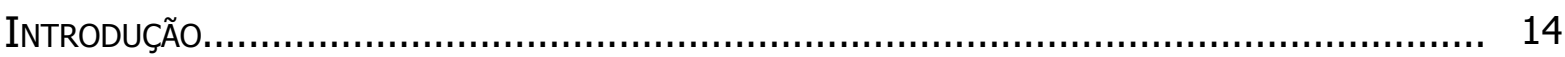

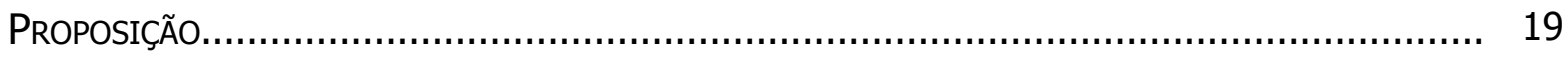

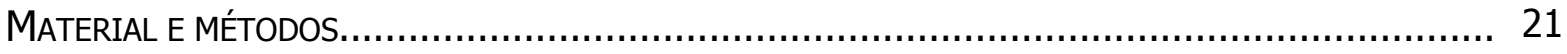

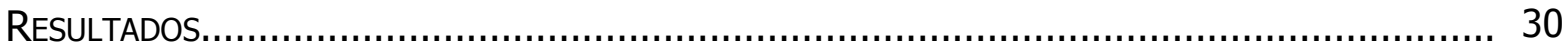

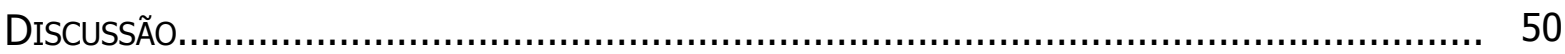

CoNCLUSÃO

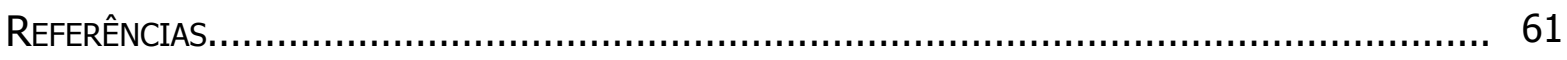

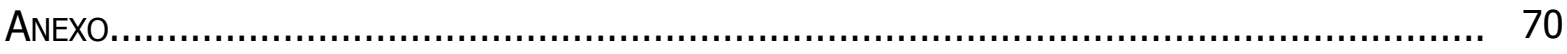




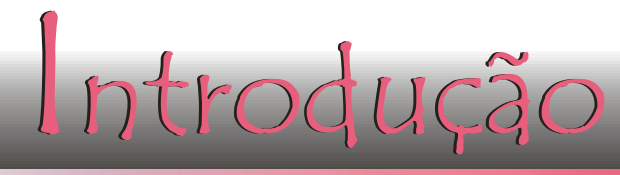




\section{INTRODUÇÃO}

A cimentação é um procedimento clínico que visa a fixação de uma restauração indireta à parte coronária ou radicular do elemento dental por meio de um agente cimentante previamente selecionado (Bottino e Brunetti, 1986). A retenção das restaurações protéticas é obtida principalmente por meio do embricamento mecânico, no interior das irregularidades das superfícies internas das restaurações e dos preparos nos elementos dentais (Christensen, 1991).

Além da biocompatibilidade, o cimento deve apresentar propriedades físico-químicas como módulo de elasticidade semelhante à dentina, adesão química e/ou micromecânica à dentina, atividade antibacteriana, resistência mecânica às forças oclusais, copolimerização com o material restaurador à base de resina e baixa solubilidade (Costa et al., 2006).

Atualmente, para cimentação de peças protéticas, são utilizadas quatro categorias de materiais: à base de óxido de zinco e eugenol (Shillingburg, 1986; Christensen, 1991; Rosenstiel et al., 1998; Sarrami et al., 2002), de fosfato de zinco, de ionômero de vidro e de resina (Christensen, 1991, Navarro e Pascotto, 1998; Rosenstiel et al., 1998; Balbosh et al., 2005).

O cimento de óxido de zinco/eugenol é comprovadamente anódino e não irritante à polpa, se empregado à distância, e esta desejável característica pode ser atribuída, pelo menos em parte, ao fato de que é mínima a presença de bactérias em cavidades vedadas com esse cimento (Mondelli, 1998; Pameijer e Wendt Jr, 1995). Entretanto, não são rotineiramente utilizados para cimentações definitivas, devido à sua baixa resistência à compressão (Christensen, 1991; Li e White, 1999).

O cimento de fosfato de zinco, introduzido em 1878, tem sido utilizado para cimentação, com bons resultados clínicos. No entanto, apesar da sua elevada resistência à compressão e à tensão (Phillips et al., 1968), este cimento apresenta características 
indesejáveis, tais como alta solubilidade (Norman et al., 1969; Yanikoglu e Yesil, 2007) e baixa adesividade (Phillips et al., 1987; Piwowarczyk et al., 2004). Além disso, apresenta pH altamente ácido (cerca de 3,5) no momento da cimentação (Norman et al., 1966; Hiraishi et al., 2003) e rápida penetração de ácido fosfórico na dentina (Smith e Ruse, 1986; Hiraishi et al., 2003), o que pode ocasionar sensibilidade pós-operatória ou alterações pulpares patológicas (Smith, 1971; Stanley, 1990; Murray et al., 2002).

No início dos anos 70, Wilson e Kent (1971) introduziram os cimentos de ionômero de vidro, os quais apresentam como vantagens a adesão química ao elemento dental (Wasson et al., 1990; Mount, 1994; Kilpatrick, 1996; Tyas, 2003; Menezes et al., 2006), liberação de flúor (Gonzalez, 1993; Mount, 1994; Kilpatrick, 1996; Chan et al., 2006), propriedades mecânicas satisfatórias, coeficiente de expansão térmica semelhante à dentina (Gonzalez, 1993; Mount, 1994; Piwowarczyk, 2001) e são facilmente removidos da área circundante, após cimentação (Kilpatrick, 1996). A adesão à estrutura dental tem sido considerada uma propriedade importante, uma vez que promove um melhor vedamento na interface dente/material dificultando a penetração bacteriana (Massara et al., 1997).

Estudos têm mostrado que os materiais ionoméricos liberam flúor constantemente e por longos períodos (Forsten, 1977 e 1998; Xu e Burgess, 2003). Por serem à base de água, são considerados como reservas contínuas de fluoreto na cavidade bucal, pela captação de flúor na saliva originado de dentifrícios, enxagüatórios e soluções tópicas de flúor (Mount, 1995; Marinelli et al., 1997; Donly et al., 1997; Xu e Burgess, 2003).

Desde o desenvolvimento do cimento de ionômero de vidro, diferentes pesquisas têm relatado seu reduzido efeito irritante junto ao tecido pulpar (Tobias et al., 1978; Hosoda et al., 1991; Shimada, 1992; Massara et al., 1997; Costa et al., 2007), semelhante ao produzido pelos cimentos de policarboxilato de zinco (Plant et al., 1984). A suave reação apresentada pelos cimentos de ionômero de vidro tem permitido a indicação dos mesmos como materiais restauradores intracoronários sem a necessidade de base (McLean, 1984; 
Felton et al., 1991), embora respostas inflamatórias moderadas (Massara et al., 1997; Costa et al., 2007) na polpa tenham sido relatadas em alguns estudos em humanos (Cooper, 1980; Plant et al., 1984; Costa et al., 2007).

Os ionômeros indicados para cimentação produzem sensibilidade pós-operatória, principalmente em cavidades muito profundas, que pode durar desde poucas horas a vários dias (McLean, 1991; Gonzalez, 1993), sendo esta sensibilidade maior quando se emprega os ionômeros anidros (McLean, 1991). Esta sensibilidade tem sido atribuída a fatores como espessura delgada de cimento, baixo pH inicial, velocidade de presa, pressão hidrostática nos túbulos dentinários, microinfiltração, solubilização de íons cálcio e alumínio, desidratação dos túbulos dentinários por captação da água durante o endurecimento (Simmons, 1988; McLean, 1991), entre outras (Gonzalez, 1993).

Recentemente, novos cimentos ionoméricos utilizados para cimentação têm sido introduzidos no mercado odontológico, como o Ketac ${ }^{\top M}$ Cem Easymix - 3M ESPE. Entretanto, os trabalhos que avaliam esse cimento são escassos e restritos à avaliação de suas propriedades físico-químicas (Balbosh et al., 2005). Portanto, ainda são necessários mais estudos, particularmente sobre sua biocompatibilidade, visto que é um tipo de material de uso rotineiro no consultório odontológico, particularmente em preparos profundos, o que permite um contato maior dos seus componentes com a polpa dental.

Os materiais para cimentação à base de resina são amplamente utilizados para a fixação de inlays, onlays, coroas, pinos e facetas. Esses cimentos resinosos são aplicados utilizando um adesivo e condicionamento ácido com enxágüe ou um adesivo autocondiocionante utilizado com uma resina composta de baixa viscosidade (De Munk et al., 2004). Esta técnica de aplicação de múltiplos passos, por ser complexa e sensível, pode comprometer a efetividade da adesão (Mak et al., 2002) e, assim, recentemente, um novo cimento à base de resina foi proposto, o qual combina o uso do adesivo e do cimento em uma única aplicação, eliminando a necessidade de um pré-tratamento tanto do dente quanto 
da restauração (De Munk et al., 2004). Esse tipo de material apresenta uma reação secundária que proporciona adesão química à hidroxiapatita (RelyX ${ }^{\mathrm{TM}}$ Unicem - 3M ESPE), uma característica atualmente só comprovada para os cimentos à base de cimentos de ionômero de vidro (Wilson et al., 1983; Yoshida et al., 2000).

Entretanto, na literatura, a maioria dos trabalhos avalia as propriedades físico-químicas desse cimento recentemente introduzido no mercado (De Munck et al., 2004; Komine et al., 2004; Goracci et al., 2004; Behr et al., 2004; Kumbuloglu et al., 2005; Lüthy et al., 2005; Piwowarczyk et al., 2005; Burke et al., 2006; Sadek et al., 2006; Naumann et al., 2006; Escribano e de la Macorra, 2006; Goracci et al, 2006; Baldissara et al., 2006; Gerth et al., 2006; de Durão Mauricio et al., 2007; Al-Assaf et al., 2007; Piwowarczyk et al, 2007; Hikita et al., 2007), sendo necessária a realização de pesquisas que avaliem sua biocompatibilidade.

A difusão intratubular de componentes resinosos de materiais à base de resina tem sido demonstrada em vários estudos (Gerzina e Hume, 1996; Bouillaguet et al., 1996; Costa et al., 2003). Além disso, estudos realizados em dentes humanos também têm mostrado, por microscopia eletrônica de varredura, ou por microscopia ótica, que componentes do sistema adesivo, aplicados em dentina profunda, podem difundir através dos túbulos dentinários e alcançar o tecido pulpar (Tay et al., 1994; Costa et al., 1999; Costa et al., 2001).

Tendo em vista a importância clínica da adequada seleção de materiais utilizados para cimentação protética, torna-se fundamental a avaliação da biocompatibilidade de diferentes agentes cimentantes atualmente introduzidos no comércio especializado. 
Proposiç्ุ̃o 


\section{Proposição}

O objetivo desse trabalho foi avaliar a biocompatibilidade de diferentes agentes cimentantes:

1. microscópica e radiograficamente, após aplicação em cavidades profundas, próximas à polpa, em dentes de cães; e

2. microscopicamente, por meio de implantes em tecido conjuntivo subcutâneo de camundongos isogênicos. 
Mąteriale Métodos 


\section{Material e Métodos}

\section{Estudo em Tecido Conjuntivo Subcutâneo de Camundongos Isogênicos}

Neste estudo foram utilizados 40 camundongos isogênicos da linhagem BALB/C, fêmeas, com 6 a 8 semanas de idade, pesando de 15 a 20 gramas, provenientes do Biotério Central da Faculdade de Medicina de Ribeirão Preto - USP, os quais foram divididos em 9 grupos com 3 períodos experimentais.

Cada animal recebeu um implante de tubo de polietileno na região dorsal contendo um dos materiais a serem testados (Ketac ${ }^{\mathrm{TM}}$ Cem Easymix e RelyX ${ }^{\mathrm{TM}}$ Unicem), nos períodos de 7, 21 e 63 dias. Tubos de polietileno vazios foram utilizados como controle.

A tabela 1 apresenta a distribuição dos grupos.

Tabela 1 - Distribuição dos grupos

\begin{tabular}{cccc}
\hline Grupos & Material experimental & No. de animais $^{\circ}$ & Período \\
\hline I & Ketac $^{\mathrm{TM}}$ Cem Easymix - 3M ESPE & 5 & 7 dias \\
II & RelyX $^{\mathrm{TM}}$ Unicem - 3M ESPE & 5 & 7 dias \\
III & Tubo de polietileno vazio & 2 & 7 dias \\
IV & Ketac $^{\mathrm{TM}}$ Cem Easymix - 3M ESPE & 6 & 21 dias \\
V & RelyX $^{\mathrm{TM}}$ Unicem - 3M ESPE & 6 & 21 dias \\
VI & Tubo de polietileno vazio $^{\mathrm{T}}$ Cem Easymix - 3M ESPE & 2 & 21 dias \\
VII & Ketac $^{\mathrm{M}}$ Cem & 6 & 63 dias \\
VIII & RelyX $^{\mathrm{TM}}$ Unicem - 3M ESPE & 6 & 63 dias \\
IX & Tubo de polietileno vazio & 2 & 63 dias \\
\hline
\end{tabular}

Preparo dos Tubos de Polietileno

Foram utilizados tubos de polietileno de $2 \mathrm{~mm}$ de diâmetro interno, os quais tiveram uma extremidade fechada com o auxílio de uma pinça clínica aquecida e cortados com $1 \mathrm{~cm}$ de comprimento. Após serem esterilizados por óxido de etileno, os tubos foram preenchidos com os materiais a serem testados. 


\section{Procedimento Operatório}

Para o ato cirúrgico, os animais foram anestesiados por inalação com éter etílico. Em seguida, foram realizadas a tricotomia da pele do dorso e a anti-sepsia da região com gluconato de clorexidina a $1 \%$.

O procedimento cirúrgico consistiu em uma incisão de $1 \mathrm{~cm}$, efetuada com tesoura cirúrgica, na região lombar do dorso do animal, seguida de divulsão com tesoura romba. Após posicionar o tubo no interior do tecido, com auxílio de pinça clínica, a pele foi suturada com fio de seda (Vicryl 4-0 - Ethicon - Johnson \& Johnson).

Os animais permaneceram no Biotério da Faculdade de Odontologia de Ribeirão Preto - USP, durante os períodos experimentais, com alimentação e água ad libittum.

Ao final de cada um dos períodos experimentais (7, 21 e 63 dias), os animais (de acordo com a tabela 1) foram novamente anestesiados, para remoção da porção do tecido conjuntivo subcutâneo, pele e tubo de polietileno. Em seguida, os animais foram mortos por inalação com éter etílico. O tecido removido foi imediatamente submetido ao processamento histotécnico.

\section{Processamento histotécnico}

As peças foram submetidas ao processamento histotécnico de rotina, ou seja, incluídas em parafina, sendo retirados os tubos de polietileno, e cortadas seriadamente com uma espessura de 5 micrometros. Os cortes foram corados pela Hematoxilina e Eosina.

\section{Análise microscópica}

A análise microscópica qualitativa, efetuada em microscópio óptico, foi baseada na resposta do tecido conjuntivo em contato com os materiais, de forma descritiva, levandose em consideração os seguintes parâmetros: infiltrado inflamatório (celularidade e tipo de célula) e reparo tecidual. 


\section{Estudo em dentes de cães}

\section{Procedimentos operatórios}

Após aprovação do projeto de pesquisa pela Comissão de Ética no Uso de Animais da Universidade de São Paulo - Campus de Ribeirão Preto, processo nº 05.1.1322.53.9 (Anexo A), foram selecionados os segundos e terceiros pré-molares superiores, e segundos, terceiros e quartos pré-molares inferiores de 4 cães, de ambos os gêneros, sem raça definida, com 12 meses de idade e pesando, em média, de 8 a 10 quilos. Deste modo, foram utilizados 40 dentes (80 raízes) distribuídos em 6 grupos, conforme descrito na Tabela 2.

Tabela 2 - Distribuição dos grupos

\begin{tabular}{cccc}
\hline Grupos & Material experimental & No. de dentes (raízes) & Período \\
\hline I & Ketac $^{\mathrm{TM}}$ Cem Easymix - 3M ESPE & 8 dentes (16 raízes) & 7 dias \\
II & RelyX $^{\mathrm{TM}}$ Unicem - 3M ESPE & 4 dentes (8 raízes) & 7 dias \\
III & Cimento de óxido de zinco e eugenol & 4 dentes (8 raízes) & 7 dias \\
IV & Ketac $^{\mathrm{TM}}$ Cem Easymix - 3M ESPE & 8 dentes (16 raízes) & 70 dias \\
V & RelyX ${ }^{\mathrm{TM}}$ Unicem - 3M ESPE & 4 dentes (8 raízes) & 70 dias \\
VI & Cimento de óxido de zinco e eugenol & 4 dentes (8 raízes) & 70 dias \\
\hline
\end{tabular}

Os animais receberam vermífugos (Drontal ${ }^{\circledR}$ Puppy - Bayer - São Paulo - Brasil), vitaminas (Glicopan ${ }^{\circledR}$ Pet - Vetnil Indústria e Comércio de Pordutos Veterinários Ltda. Louveira - Brasil) e vacinas anti-rábica (Rai-Vac $\mathrm{I}^{\circledR}$ - Fort Dodge - Campinas - Brasil) e tríplice (Vanguard $^{\circledR}$ HTLP 5/CV-L - Laboratórios Pfizer Ltda. - Guarulhos - Brasil) em 3 doses, com 3 semanas de intervalo entre cada aplicação. Os cães fora mantidos no Biotério da Faculdade de Odontologia de Ribeirão Preto da Universidade de São Paulo com livre acesso à água e com dieta padrão da Unidade durante todo o período de experimentação. 
Inicialmente os animais foram pré-anestesiados, por meio de injeção intramuscular de 2,0mL de Rompum ${ }^{\circledR}$ (Cloridrato de Dihidrotiazina - Bayer S/A - Produtos Veterinários - São Paulo - Brasil), na dosagem de 3,0mg/kg de peso, 30 minutos antes do ato operatório. A seguir, por via endovenosa, foi efetuada a anestesia geral com Thionembutal ${ }^{\circledR}$ (Thipental Sódico - Abbot Laboratórios do Brasil Ltda. - Rio de Janeiro - Brasil) na dosagem de $30 \mathrm{mg} / \mathrm{kg}$ de peso e, quando necessário, foi realizada a suplementação anestésica. Durante todo o ato operatório, os animais foram mantidos com solução isotônica de cloreto de sódio a 0,9\% (Glicolabor Indústria Farmacêutica Ltda. - Ribeirão Preto - Brasil).

A seguir, foi efetuado o exame radiográfico periapical dos dentes a serem utilizados no estudo, empregando o dispositivo para padronização de tomadas radiográficas em cães, descrito por Cordeiro et al. (1995). Foram utilizados filmes periapicais Ultraspeed ${ }^{\circledR}$ tamanho 2 (Eastman Kodak Company - Rochester - USA), aparelho de raios-X odontológico Heliodent ${ }^{\circledR}$ (Siemens - New York - USA), com 60kVp e 10mA e tempo de exposição de 1 segundo. As radiografias foram reveladas pelo método tempo/temperatura e arquivadas em cartelas plásticas.

Todo o material utilizado nos procedimentos operatórios foi esterilizado em autoclave a $121^{\circ} \mathrm{C}$, por 20 minutos (Souza-Gugelmin et al., 2005). A profilaxia dental foi realizada com o objetivo de remover cálculo e biofilme, seguida pela anestesia infiltrativa complementar com Mepivacaína a 2\% com Noradrenalina 1:100.000 (Scandicaine ${ }^{\circledR}$ - Septodont Distribuidora DFL Indústria e Comércio Ltda. - Rio de Janeiro - Brasil).

Foi realizado o isolamento do campo operatório com dique de borracha, e a anti-sepsia com peróxido de hidrogênio a 3\%, seguida da aplicação de digluconato de clorexidina a $2,0 \%$.

Foram preparadas cavidades de classe $\mathrm{V}$ na face vestibular de cada dente, com 0 auxílio de uma ponta diamantada esférica n 1015 (KG Sorensen - São Paulo - Brasil) montadas em caneta de alta rotação, refrigeradas a ar e água, aprofundadas de maneira 
uniforme até que se observasse, clinicamente, a coloração rósea do tecido pulpar. A cada 4 preparos cavitários uma nova ponta diamantada era utilizada para assegurar a eficiência de corte e evitar o superaquecimento. As paredes circundantes foram submetidas ao acabamento, utilizando-se uma fresa número 56 (KG Sorensen - São Paulo - Brasil), em baixa rotação. Durante todo o procedimento de preparo da cavidade, foi evitado o desenvolvimento de calor excessivo, por meio de movimentos intermitentes das fresas. As cavidades foram, então, abundantemente irrigadas com soro fisiológico esterilizado (Glicolabor Indústria Farmacêutica Ltda. - Ribeirão Preto - Brasil), para remover fragmentos de esmalte e dentina.

Para que todas as variáveis fossem testadas em um mesmo animal, e em diferentes quadrantes, cada hemi-arco recebeu, em sistema de rodízio distribuído ao acaso, os diferentes produtos avaliados, sendo seguidas as instruções dos fabricantes.

Grupos I (7 dias) e IV (70 dias): nesses grupos foi avaliado o cimento à base de ionômero de vidro Ketac ${ }^{\mathrm{TM}}$ Cem Easymix (3M ESPE Produtos Dentários - Sumaré - Brasil). O pó (aproximadamente 1 colher rasa) foi manipulado com o líquido ( 2 gotas) em uma placa de vidro esterilizada, de acordo com a instrução do fabricante, até a obtenção de uma pasta espessa, a qual foi colocada na cavidade com o auxílio de uma cureta e acomodado com mechas de algodão esterilizadas.

Grupos II (7 dias) e IV (70 dias): nesses grupos foi avaliado o cimento resinoso RelyX ${ }^{\mathrm{TM}}$ Unicem (3M ESPE Produtos Dentários - Sumaré - Brasil). A cápsula do material foi colocada no ativador e a alavanca ativadora foi pressionada por 2-4 segundos para garantir que todo o líquido passasse do seu reservatório para o local onde havia o pó. Em seguida, a cápsula foi colocada em um amalgamador de alta freqüência (Dabi Atlante - Ribeirão Preto Brasil) durante 15 segundos, para que houvesse a mistura do material. Após a mistura, a cápsula foi inserida no aplicador para que o material pudesse ser colocado em uma placa de 
vidro esterilizada. O material foi, então, colocado na cavidade com o auxílio de uma cureta esterilizada e fotopolimerizado por 20 segundos.

Grupos III (7 dias) e VI (70 dias): nesses grupos foi avaliado o óxido de zinco e eugenol (IRM ${ }^{\circledR}$ Dentsply Indústria e Comércio Ltda. - Petrópolis - Brasil). O pó de óxido de zinco (1g) foi manipulado com eugenol (1 gota) em uma placa de vidro esterilizada, até a obtenção de uma massa espessa, a qual foi colocada e acomodada na cavidade com o auxílio de uma cureta esterilizada.

Em todos os grupos experimentais, após a colocação de cada material sobre a parede dentinária pulpar, as cavidades foram restauradas com cimento de ionômero de vidro modificado por resina (Vitremer ${ }^{\circledR}$ - 3M ESPE - Produtos Dentários - Sumaré - Brasil), manipulado e utilizado de acordo com as instruções do fabricante. Após o término dos procedimentos operatórios foi efetuado o exame radiográfico periapical padronizado.

Os animais foram acompanhados durante todo o período experimental para observação de possíveis mudanças de hábitos alimentares, desenvolvimento de processos inflamatórios ou supuração dos tecidos, dentre outras anormalidades.

Decorridos os períodos experimentais de 7 (Grupos I, II e III) e 70 dias (Grupos IV, V e VI) as hemi-arcadas foram radiografadas, da mesma maneira descrita anteriormente, e os animais foram mortos por sobredose anestésica de Thionembutal ${ }^{\circledR}$. As maxilas e mandíbulas foram dissecadas, com auxílio de um bisturí, reduzidas em seu volume e as peças lavadas em água corrente. Para facilitar o processamento histotécnico, as peças foram seccionadas utilizando discos diamantados, sob constante refrigeração com água, sendo obtidos blocos das peças anatômicas contendo os dentes individualmente.

\section{Processamento histotécnico}

As peças foram submetidas à fixação com formol tamponado a $10 \%$, por 72 horas, à temperatura ambiente. Posteriormente, as peças foram imersas em um recipiente de vidro contendo uma solução à base de EDTA (ácido etilenodiaminotetracético) a 10\%, composta 
de EDTA (EDTA Disodium Salt Dihydrate - Merk - Darmstadt - Alemanha), água destilada e hidróxido de sódio (Hidróxido de sódio p.a. ${ }^{\circledR}$ - Casa da Química Ind. e Com. Ltda. - Diadema - Brasil) e submetidas à desmineralização, acelerada pelo forno microondas (Sharp Carousel ${ }^{\circledR}$ - São Paulo - Brasil). Para a realização deste procedimento, o recipiente contendo as peças foi parcialmente submerso em outro recipiente de vidro contendo água e gelo, com o objetivo de retardar o aumento da temperatura e, conseqüentemente, incrementar o tempo de ação do microondas. O forno microondas foi operado na freqüência de trabalho de $2450 \mathrm{MHz}$, correspondendo a uma freqüência de onda no vácuo de $12,2 \mathrm{~cm}$, potência máxima nominal de $700 \mathrm{~W}$, regulado em potência média/máxima à temperatura de $30^{\circ} \mathrm{C}$, para evitar alterações teciduais. As peças foram irradiadas por 10 minutos, com intervalos de 5 minutos entre as irradiações, por um período de 4 horas/dia.

A completa desmineralização das amostras foi avaliada por meio da penetração de uma agulha nos tecidos para verificação da sua consistência e por meio de exame radiográfico das peças. Concluída a desmineralização, as peças foram neutralizadas em solução de sulfato de sódio a 5\% (Sulfato de Sódio Anhido - J.T.BaKer - Xalostoc - México) por 24 horas, lavadas em água corrente por 24 horas, desidratadas em concentrações crescentes de álcool (Álcohol Etílico Absoluto Anhidro ${ }^{\circledR}$ - J.T.BaKer - Xalostoc - México) , diafanizadas em xilol (Xylol - Merck - Darmstadt - Alemanha) e incluídas em parafina (Histosec ${ }^{\circledR}$ Pastillen - Merck - Darmstadt - Alemanha) de acordo com a rotina histotécnica. Os blocos contendo os dentes individualizados foram reduzidos pela microtomia a cortes seriados longitudinais com 5,0 micrometros de espessura. Para avaliação microscópica, as lâminas foram coradas pela Hematoxilina e Eosina ( $\mathrm{HE})$, Tricrômio de Mallory e pelo método de Brown \& Brenn e observadas em microscópio óptico. 


\section{Análise microscópica}

A análise microscópica foi realizada por microscopia ótica, sem conhecimento prévio do espécime. Para cada série de secções, foi registrada a descrição completa das características da dentina, polpa e tecidos periapicais de acordo com os seguintes aspectos: 1 - Presença de polpa normal; 2 - Presença de dentina reacional; 3 - Presença de ulceração; 4 - Pulpite; 5 - Presença de necrose pulpar. Os resultados obtidos foram submetidos à análise estatística por meio do teste exato de Fisher, com nível de significância de 5\%.

\section{Avaliação radiográfica}

A avaliação radiográfica foi realizada utilizando as radiografias periapicais obtidas previamente à execução dos atos operatórios e após 7 dias e 70 dias da intervenção. As radiografias foram examinadas por 3 examinadores calibrados, com relação à presença ou ausência de lâmina dura, de áreas de rarefação óssea periapical e de reabsorções radiculares (interna e externa). A concordância entre os examinadores foi determinada pelo teste Kappa.

Para mensuração das lesões periapicais, quando presentes, as radiografias das hemiarcadas, obtidas previamente à morte dos animais, foram digitalizadas com auxílio de scanner óptico (Hewlett-Packard - Scanjet7450 c series - programa versão 3.0.2 - San Diego - CA) e transferidas para o programa Imaje J 1.37 u (National Institutes of Health USA). Com o objetivo de calibrar o programa foi realizada a medida da distância da ponta da cúspide até a borda cervical da face distal de cada dente, com compasso de ponta seca, sendo esta medida transferida para o programa. A delimitação e a medida da área radiolúcida sugestiva de lesão periapical, presente em cada raiz foi determinada em $\mathrm{mm}^{2}$. 
Resultados 


\section{Resultados}

\section{Do Estudo em Tecido Conjuntivo Subcutâneo de Camundongos Isogênicos}

A reação tecidual frente ao implante dos diferentes materiais (Ketac ${ }^{\mathrm{TM}}$ Cem Easymix e RelyX Unicem ${ }^{\mathrm{TM}}$ ) analisados nos períodos de 7, 21 e 63 dias, encontram-se descritos a seguir.

Ketac $^{T M}$ Cem Easymix

Os cortes teciduais revelam, na periferia do material após 7 dias, grande acúmulo de leucócitos, predominantemente polimorfonucleares do tipo neutrófilos com eventuais macrófagos e linfócitos de permeio (Fig. 1A e 1B).

Aos 21 dias, nota-se formação de tecido de granulação com moderado grau de colagenização (linha). Além dos macrófagos e linfócitos, nota-se ainda o elevado número de fibroblastos jovens permeados também por neutrófilos eventuais (Fig. 1C e 1D).

Após os 63 dias, o tecido conjuntivo reacional derivado do tecido de granulação aumentou seu grau de fibrosamento, mas com eventuais pequenos granulomas do tipo corpo estranho (círculo) em sua porção mais periférica. Na cápsula representada pelo tecido conjuntivo fibroso notam-se macrófagos, eventuais linfócitos e raros neutrófilos (Fig. 1E e 1F).

Em suma, nota-se ao redor do material a formação de uma espessa camada de tecido de granulação e conjuntivo reacionais com infiltração considerável de leucócitos mesmo no período mais tardio. 
RelyX $X^{T M}$ Unicem

Aos 7 dias, o tecido periférico reacional ao material revela pequena espessura (setas) e elevado grau de colagenização considerando-se a brevidade do processo. No tecido de granulação periférico ao material há discreta infiltração de leucócitos polimorfonucleares tipo neutrófilos e moderada presença de macrófagos entre os fibroblastos jovens (Fig. 2A, 2B e 2C). Destaca-se também a presença de eosinófilos.

Aos 21 dias o padrão reacional se assemelha (setas) ao do período de 7 dias, destacando-se novamente a presença de eosinófilos (Fig. 2D e 2E).

Aos 63 dias, o tecido conjuntivo reacional perimaterial se apresenta bem mais fino e densamente colagenizado (setas). A infiltração de leucócitos polimorfonucleares tipo neutrófilos não foi observada, encontrando-se moderado número de macrófagos de permeio aos fibroblastos jovens (Fig. 2F).

Em suma, desde os 7 dias até 63 dias a resposta tecidual induzida foi muito discreta.

Controle (tubo de polietileno vazio)

Aos 7 dias, o tecido de granulação periférico ao material revela-se com larga espessura se comparado aos grupos experimentais e entremeado por formações granulomatosas do tipo corpo estranho com rica população de macrófagos dispostos em aglomerados pouco organizados (círculos). De permeio aos fibroblastos e macrófagos, nota-se grande quantidade de leucócitos polimorfonucleares tipo neutrófilos (Fig. 3A, 3B e 3C).

Aos 21 dias, a espessura do tecido de granulação reduziu-se grandemente com presença de células gigantes multinucleadas inflamatórias (setas) na interface com o tubo de polietileno (TP). Os macrófagos estão distribuídos de forma esparsa e limitada à cápsula 
fibrosa formada pelo tecido conjuntivo reacional que evoluiu a partir do tecido de granulação inicial (Fig. 3D).

Aos 63 dias, o tecido periférico ao material limita-se a uma finíssima (setas) cápsula de tecido conjuntivo fibroso com eventuais leucócitos mononucleares. As fibras colágenas são bem organizadas e densamente dispostas (Fig. 3E e 3F).

Em suma, nos primeiros dias, o tecido reacional periférico ao material é exuberante, mas nos períodos subseqüentes reduz-se de forma a comparar-se com o tecido conjuntivo fibroso normal. 


\section{Figura 1}

\section{Do estudo em tecido conjuntivo subcutâneo de camundongos}

Ketac Cem Easymix ${ }^{\circledR}$ (KCE)

A. 7 dias - Resposta inflamatória com presença acentuada de leucócitos polimorfonucleares do tipo neutrófilos.

B. Maior aumento da Fig. 1A.

C. 21 dias - Reação periférica ao material caracterizada por espessa cápsula de tecido de granulação (linhas) e conjuntivo reacionais infiltrados por neutrófilos eventuais.

D. Maior aumento da Fig. $1 \mathrm{C}$.

E. 63 dias - Presença de exuberante tecido conjuntivo reacional com intenso grau de colagenização e reações granulomatosas periféricas (círculos).

F. Maior aumento da Fig. 1E.

Coloração: H. E.

Aumentos originais: $A$ e C: $100 x$

B e E: $200 x$

D e F: $400 x$ 

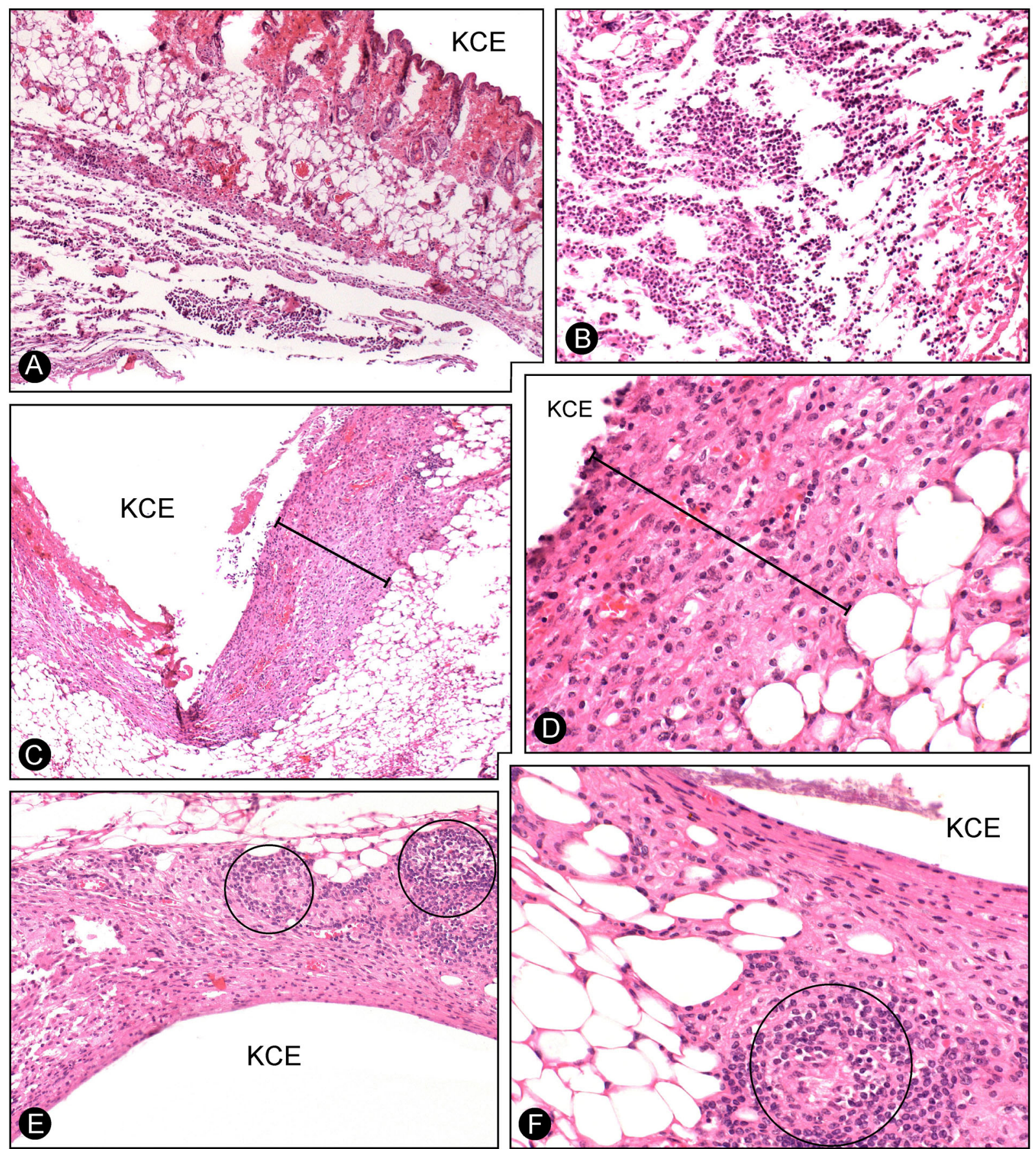


\section{Figura 2}

\section{Do estudo em tecido conjuntivo subcutâneo de camundongos}

Rely $X^{T M}$ Unicem (RXU)

A. 7 dias - Discreta reação inflamatória com presença de macrófagos,

fibroblastos e eosinófilos. A cápsula fibrosa tem pequena espessura (seta).

B. Maior aumento da Fig. 2A.

C. C-Maior aumento da Fig. 2B.

D. 21 dias - Reação inflamatória discreta com tecido conjuntivo fibroso reacional densamente colagenizado e com mínima espessura (seta).

E. Maior aumento da Fig. 2D.

F. 63 dias - Estreita faixa de tecido conjuntivo fibroso (seta) sem processo inflamatório associado e morfologicamente normal.

Coloração: H. E.

Aumentos originais: $A, D$ e F: $100 x$

B: $200 x$

C e E: $400 x$ 


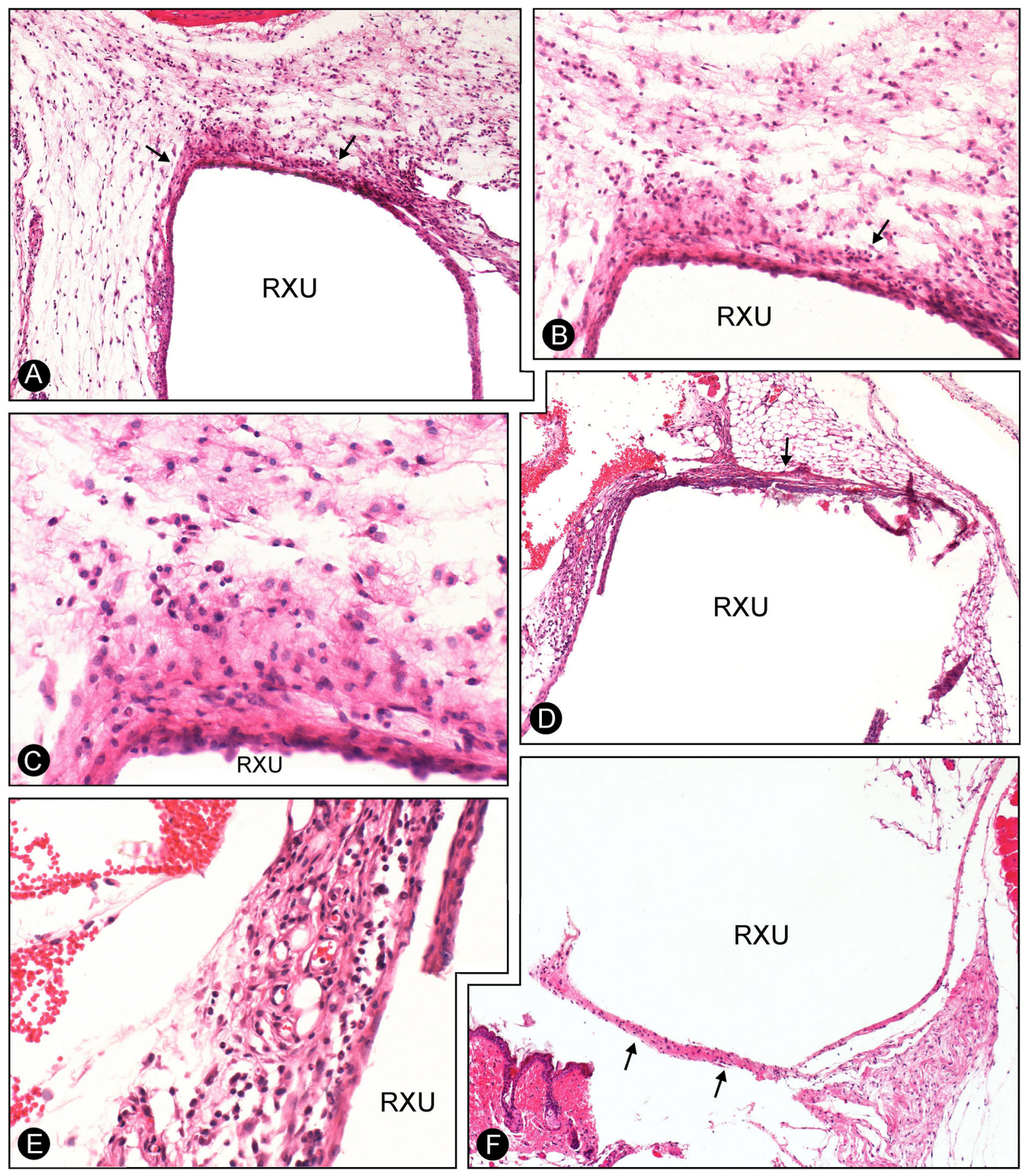




\section{Figura 3}

Do estudo em tecido conjuntivo subcutâneo de camundongos

Grupo controle (TP = tubo de polietileno)

A. 7 dias - Reação perimaterial com exuberante tecido de granulação e formações granulomatosas (círculos).

B. Maior aumento da Fig. 3A.

C. Maior aumento da Fig. 3B.

D. 21 dias - Tecido conjuntivo reacional com moderado grau de colagenização e presença de células gigantes multinucleadas inflamatórias (setas) na interface com o tubo de polietileno.

E. 63 dias - Tecido conjuntivo fibroso capsular (setas) livre de inflamação e com morfologia normal.

F. F-Maior aumento da Fig. 3E.

Coloração: H. E.

Aumentos originais: $A-100 x$

$$
\begin{aligned}
& \text { B e } E-200 x \\
& C, D \text { e } F-400 x
\end{aligned}
$$



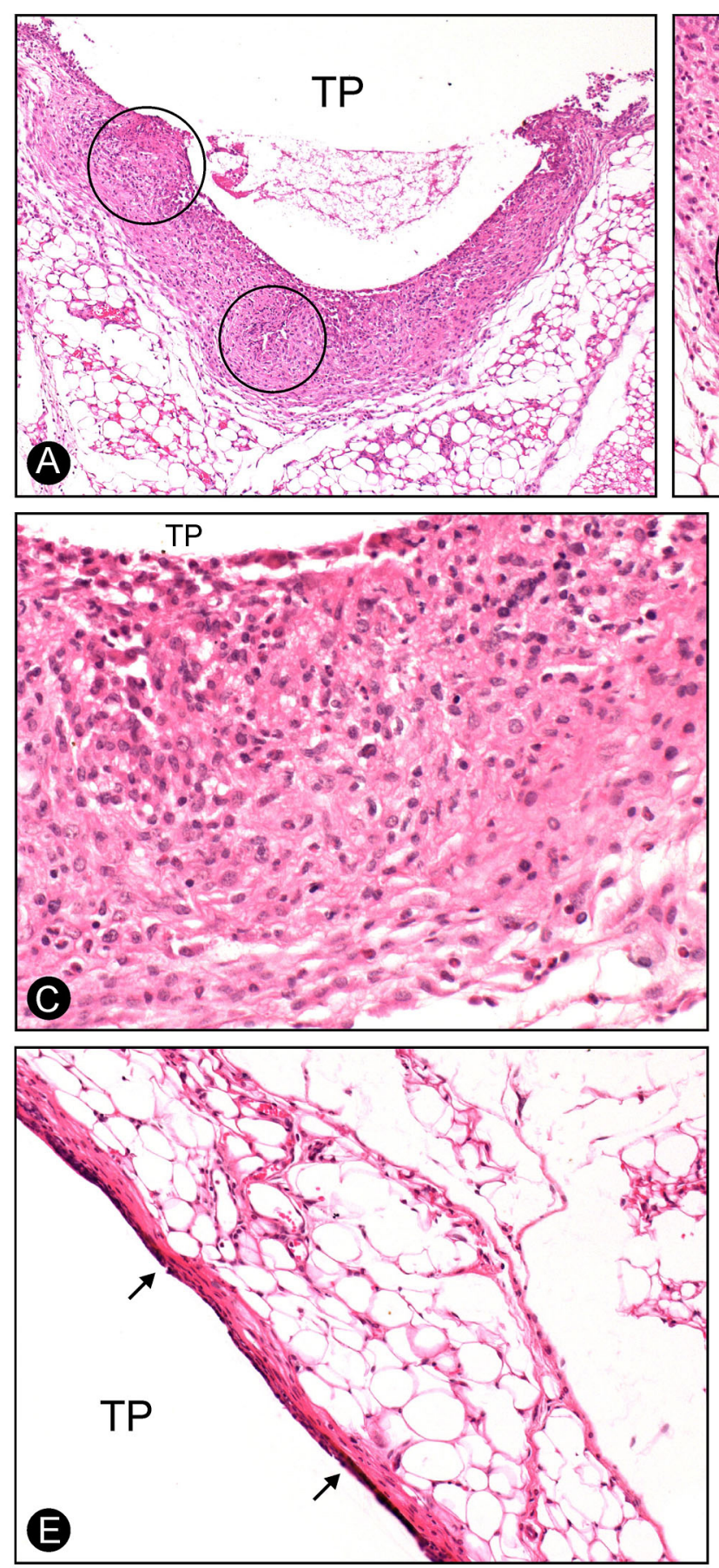
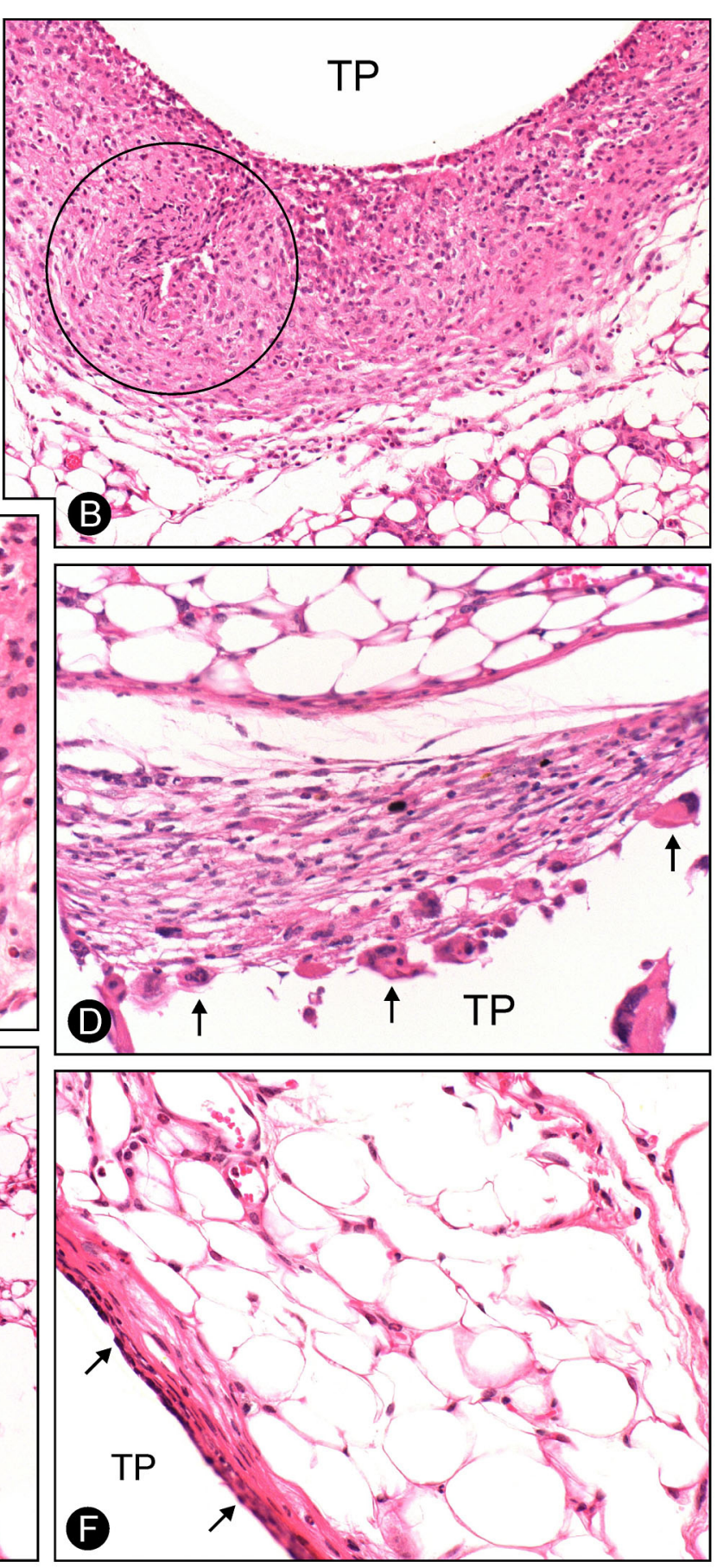


\section{Do Estudo Microscópico em Dentes de Cães}

Grupo I (Ketac ${ }^{T M}$ Cem Easymix - 7 dias)

Das 16 raízes desse grupo, 4 foram perdidas durante o processamento histotécnico, sendo analisado um total de 12 raízes.

No período de 7 dias, a polpa apresentava características de normalidade, sendo observada a presença de eventuais focos hemorrágicos em 4 espécimes e vacuolização odontoblástica em outros 4 espécimes. Não foi evidenciada a presença de microrganismos em nenhum dos espécimes avaliados nas colorações realizadas (Fig. 4A, 4B e 4C).

Grupo II (RelyX $X^{T M}$ Unicem - 7 dias)

Das 16 raízes desse grupo, 2 foram perdidas durante o processamento histotécnico. Nas 14 raízes restantes a polpa apresentava aspecto normal. A morfologia do material com seus cristais birrefringentes e matriz basofílica e eosinofílica foi observada em 6 espécimes. Não foi evidenciada a presença de microrganismos em nenhum dos espécimes avaliados nas colorações realizadas (Fig. 5A, 5B, 5C e 5D).

Grupo III (Cimento de Óxido de zinco e Eugenol - 7 dias)

Das 8 raízes desse grupo, um total de 4 espécimes apresentou-se normal, apenas com áreas de vacuolização odontoblástica e alterações reticulares. Por outro lado, congestão vascular, áreas de vacuolização odontoblástica, áreas de ulceração e inflamação foram vistas nos outros 4 espécimes. Não foi evidenciada a presença de microrganismos em nenhum dos espécimes avaliados nas colorações realizadas (Fig. 6A, 6B e 6C). 
A Tabela 3 apresenta os resultados microscópicos observados nos espécimes dos grupos I, II e III (período de 7 dias), com relação aos parâmetros avaliados e a comparação entre os grupos, para cada parâmetro, utilizando-se o teste exato de Fisher $(p<0,05)$.

Tabela 3 - Resultados da análise microscópica observados aos 7 dias, com relação aos parâmetros avaliados e da comparação entre os grupos.

\begin{tabular}{|c|c|c|c|c|c|c|}
\hline Grupos & $\begin{array}{l}\text { №. de } \\
\text { raízes } \\
(\%)\end{array}$ & $\begin{array}{c}\text { Tecido } \\
\text { Pulpar } \\
\text { Normal } \\
(\%)\end{array}$ & $\begin{array}{c}\text { Dentina } \\
\text { Reacional } \\
(\%)\end{array}$ & $\begin{array}{c}\text { Tecido } \\
\text { Pulpar com } \\
\text { Ulceração } \\
\text { (\%) }\end{array}$ & $\begin{array}{c}\text { Inflamaçã } \\
\text { o Pulpar } \\
\text { (\%) }\end{array}$ & $\begin{array}{c}\text { Necrose } \\
\text { Pulpar } \\
(\%)\end{array}$ \\
\hline Grupo I (Ketac ${ }^{\mathrm{TM}}$ Cem) & $\begin{array}{c}12 \\
(100 \%)\end{array}$ & $\begin{array}{c}12 \\
(100 \%)\end{array}$ & 0 & 0 & 0 & 0 \\
\hline $\begin{array}{c}\text { Grupo II (RelyX }{ }^{\mathrm{TM}} \\
\text { Unicem) }\end{array}$ & $\begin{array}{c}14 \\
(100 \%)\end{array}$ & $\begin{array}{c}14 \\
(100 \%)\end{array}$ & 0 & 0 & 0 & 0 \\
\hline $\begin{array}{l}\text { Grupo III (Óxido de } \\
\text { zinco e eugenol) }\end{array}$ & $\begin{array}{c}8 \\
(100 \%)\end{array}$ & $\begin{array}{c}4 \\
(50 \%)\end{array}$ & 0 & $\begin{array}{c}4 \\
(50 \%)\end{array}$ & $\begin{array}{c}4 \\
(50 \%)\end{array}$ & 0 \\
\hline$p^{*}$ & N.A. & 0,0015 & N.A & 0,0015 & 0,0015 & N.A \\
\hline
\end{tabular}

* $p$ : valor de $\mathrm{p}$ para teste exato de Fisher comparando os três grupos experimentais.

N.A.: não avaliado

A comparação entre os grupos mostrou que houve diferença estatisticamente significante entre eles $(p<0,05)$, com relação à normalidade da polpa, presença de tecido pulpar com ulceração e presença de inflamação pulpar. No entanto, essa diferença se deve ao grupo III, pois os grupos I e II apresentaram comportamentos semelhantes.

Grupo IV (Ketac ${ }^{T M}$ Cem Easymix - 70 dias)

Das 16 raízes desse grupo, foram avaliadas 14 raízes, em função da perda de 2 durante o processamento histotécnico. 
No período de 70 dias, o tecido pulpar encontrava-se normal em 10 espécimes, estando a camada odontoblástica discretamente vacuolada e o tecido conjuntivo bem preservado, com ausência de sinais de inflamação e de necrose. Observou-se depósito de dentina reacional em 6 espécimes. Observou-se a presença de material amorfo na cavidade, com cristais birrefringentes, semelhantes a vidro. Nos 4 espécimes em que ocorreu microexposição pulpar, a polpa apresentou-se com áreas de inflamação com intenso infiltrado neutrofílico e extensas áreas de necrose. Além disso, nesses casos observou-se presença de reação periapical (abscesso periapical) com muitas áreas de reabsorção apical e reabsorções óssea, associada à presença de acúmulo de pus na polpa. Observou-se ulceração em 4 espécimes. Não foi evidenciada a presença de microrganismos em nenhum dos espécimes avaliados nas colorações realizadas (Fig. 4D, 4E, 4F, 4G, 4H e 4I)

Grupo V (RelyX $X^{T M}$ Unicem - 70 dias)

Nos 16 espécimes desse grupo, em 12 a polpa apresentou-se preservada em sua organização e estrutura, sem sinais de inflamação ou necrose, com o periodonto também preservado. Houve deposição de dentina reacional em 8 espécimes. Exposição pulpar foi observada em 4 casos, os quais apresentaram áreas de inflamação pulpar e áreas de necrose pulpar com abscesso e ampla lesão periapical, com extensas áreas de reabsorção apical. Observou-se, nesses casos, neutrófilos no terço apical do canal radicular (necrose purulenta). Não foi evidenciada a presença de microrganismos em nenhum dos espécimes avaliados nas colorações realizadas (Fig. 5E e 5F).

Grupo VI (Cimento de Óxido de zinco e eugenol - 70 dias)

Das 8 raízes desse grupo, a polpa apresentou-se normal em 6 casos, com depósitos de dentina reacional em 4 espécimes. Ocorreu microexposição pulpar em 2 casos, estando a 
camada odontoblástica destruída focalmente. Nesses casos, na parede da cavidade, notou-se interação do material com a dentina, caracterizada por formações esféricas, birrefringentes e basofílicas em uma matriz rósea e hialina. Nos casos em que houve microexposição pulpar, pôde-se notar a introdução de raspas de dentina e instalação de ulceração e inflamação pulpar. Não foi evidenciada a presença de microrganismos em nenhum dos espécimes avaliados nas colorações realizadas (Fig. 6D e 6E).

A Tabela 4 apresenta os resultados microscópicos observados nos espécimes dos grupos VI, V e VI (período de 70 dias), com relação aos parâmetros avaliados e a comparação entre os grupos, para cada parâmetro, utilizando-se o teste exato de Fisher $(p<0,05)$.

Tabela 4 - Resultados da análise microscópica observados aos 70 dias, com relação aos parâmetros avaliados e a comparação entre os grupos.

\begin{tabular}{|c|c|c|c|c|c|c|}
\hline Grupos & $\begin{array}{l}\mathrm{N}^{\circ} . \text { de } \\
\text { raízes } \\
(\%)\end{array}$ & $\begin{array}{c}\text { Tecido } \\
\text { Pulpar } \\
\text { Normal } \\
(\%)\end{array}$ & $\begin{array}{c}\text { Dentina } \\
\text { Reacional } \\
(\%)\end{array}$ & $\begin{array}{c}\text { Tecido } \\
\text { Pulpar } \\
\text { com } \\
\text { Ulceração } \\
\text { (\%) }\end{array}$ & $\begin{array}{c}\text { Inflamação } \\
\text { Pulpar } \\
\text { (\%) }\end{array}$ & $\begin{array}{c}\text { Necrose } \\
\text { Pulpar } \\
(\%)\end{array}$ \\
\hline $\begin{array}{c}\text { Grupo I (Ketac }{ }^{\mathrm{TM}} \text { Cem } \\
\text { Easymix) }\end{array}$ & $\begin{array}{c}14 \\
(100 \%)\end{array}$ & $\begin{array}{c}10 \\
(71,42 \%)\end{array}$ & $\begin{array}{c}6 \\
(42,85 \%)\end{array}$ & $\begin{array}{c}4 \\
(28,57 \%)\end{array}$ & 0 & $\begin{array}{c}4 \\
(28,57 \%)\end{array}$ \\
\hline $\begin{array}{c}\text { Grupo II (RelyX }{ }^{\mathrm{TM}} \\
\text { Unicem) }\end{array}$ & $\begin{array}{c}16 \\
(100 \%)\end{array}$ & $\begin{array}{c}12 \\
(75 \%)\end{array}$ & $\begin{array}{c}8 \\
(50 \%)\end{array}$ & 0 & $\begin{array}{c}4 \\
(25 \%)\end{array}$ & $\begin{array}{c}4 \\
(25 \%)\end{array}$ \\
\hline $\begin{array}{l}\text { Grupo III (Óxido de } \\
\text { zinco e eugenol) }\end{array}$ & $\begin{array}{c}8 \\
(100 \%)\end{array}$ & $\begin{array}{c}6 \\
(75 \%)\end{array}$ & $\begin{array}{c}4 \\
(50 \%)\end{array}$ & $\begin{array}{c}2 \\
(25 \%)\end{array}$ & $\begin{array}{c}2 \\
(25 \%)\end{array}$ & 0 \\
\hline$p^{*}$ & N.A. & 0,9999 & 0,9182 & 0,0229 & 0,0931 & 0,03069 \\
\hline
\end{tabular}

${ }^{*} p$ : valor de $\mathrm{p}$ para teste exato de Fisher comparando os três grupos experimentais.

N.A.: não avaliado

A análise dos dados mostrou que houve diferença estatisticamente significante entre os grupos IV, V e VI $(p<0,05)$, com relação à presença de tecido pulpar com ulceração e presença de necrose pulpar. 
Com o objetivo de avaliar se houve diferença nos resultados microscópicos, nos dois períodos experimentais, os grupos I, II e III (período de 7 dias) foram comparados respectivamente com os grupos IV, V e VI (período de 70 dias). As comparações encontramse descritas nas tabelas 5 a 9.

Tabela 5 - Comparação entre os grupos I, II e III (7 dias) com os grupos IV, V e VI (70 dias), respectivamente, com relação à normalidade do tecido pulpar.

\begin{tabular}{cccc} 
& \multicolumn{2}{c}{ Tecido Pulpar Normal } & \multirow{2}{*}{$p^{*}$} \\
& Presente & Ausente & 0,0001 \\
Grupo I & 12 & 0 & 0,1029 \\
\hline Grupo IV & 10 & 4 & 0,6084 \\
Grupo V & 14 & 0 & \\
\hline Grupo III & 12 & 4 & \multirow{2}{*}{} \\
Grupo VI & 4 & 4 & \\
\hline
\end{tabular}

* $p$ : valor de $\mathrm{p}$ para teste exato de Fisher comparando os três grupos experimentais.

A análise dos dados mostrou que, com relação à normalidade da polpa, houve diferença estatisticamente significante entre os grupos I e IV $(p<0,05)$.

Tabela 6 - Comparação entre os grupos I, II e III (7 dias) com os grupos IV, V e VI (70 dias), respectivamente, com relação à presença de dentina reacional.

\begin{tabular}{cccc} 
& \multicolumn{2}{c}{ Dentina Reacional } & \multirow{2}{*}{$p^{*}$} \\
\hline Grupo I & 0 & Ausente & 0,0171 \\
Grupo IV & 6 & 12 & \\
\hline Grupo II & 0 & 8 & 0,0027 \\
Grupo V & 8 & 14 & \multirow{2}{*}{0,0769} \\
Grupo III & 0 & 8 & \\
Grupo VI & 4 & 8 &
\end{tabular}

* $p$ : valor de $\mathrm{p}$ para teste exato de Fisher comparando os três grupos experimentais.

A análise dos dados mostrou que, com relação à presença de dentina reacional, houve diferença estatisticamente significante entre os grupos I e IV $(p<0,05)$ e entre os grupos II e $V(p<0,05)$. 
Tabela 7 - Comparação entre os grupos I, II e III (7 dias) com os grupos IV, V e VI (70 dias), respectivamente, com relação à presença de tecido pulpar com ulceração.

\begin{tabular}{cccc} 
& \multicolumn{2}{c}{ Tecido Pulpar com Ulceração } & \\
& Presente & Ausente & 0 \\
\hline Grupo I & 0 & 12 & 0,0425 \\
Grupo IV & 4 & 10 & \multirow{2}{*}{ N.A. } \\
\hline Grupo II & 0 & 14 & \\
Grupo V & 0 & 16 & 0,6084 \\
\hline Grupo III & 4 & 4 & \\
Grupo VI & 2 & 6 & \\
\hline
\end{tabular}

* $p$ : valor de $\mathrm{p}$ para teste exato de Fisher comparando os três grupos experimentais.

N.A.: não avaliado

A análise dos dados mostrou que, com relação à presença de tecido pulpar com ulceração, houve diferença estatisticamente significante entre os grupos I e IV $(p<0,05)$.

Tabela 8 - Comparação entre os grupos I, II e III (7 dias) com os grupos IV, V e VI (70 dias), respectivamente, com relação à presença de inflamação pulpar.

\begin{tabular}{|c|c|c|c|}
\hline \multicolumn{4}{|c|}{ Inflamação Pulpar } \\
\hline & Presente & Ausente & $p^{*}$ \\
\hline Grupo I & 0 & 12 & \multirow{2}{*}{ N.A. } \\
\hline Grupo IV & 0 & 14 & \\
\hline Grupo II & 0 & 14 & \multirow{2}{*}{0,1029} \\
\hline Grupo V & 4 & 12 & \\
\hline Grupo III & 4 & 4 & \multirow{2}{*}{0,6084} \\
\hline Grupo VI & 2 & 6 & \\
\hline
\end{tabular}

* $p$ : valor de $\mathrm{p}$ para teste exato de Fisher comparando os três grupos experimentais.

N.A.: não avaliado

A análise dos dados mostrou que, com relação à presença de inflamação pulpar, não houve diferença estatisticamente significante entre os grupos. 
Tabela 9 - Comparação entre os grupos I, II e III (7 dias) com os grupos IV, V e VI (70 dias), respectivamente, com relação à presença de necrose pulpar.

\begin{tabular}{cccc} 
& \multicolumn{2}{c}{ Necrose Pulpar } & \multirow{2}{*}{ Ausente } \\
\hline Grupo I & 0 & 12 & 0,1001 \\
Grupo IV & 4 & 10 & 0,1029 \\
\hline Grupo II & 0 & 14 & \\
Grupo V & 4 & 12 & N.A. \\
Grupo III & 0 & 8 & \\
Grupo VI & 0 & 8 & \\
\hline
\end{tabular}

* $p$ : valor de $\mathrm{p}$ para teste exato de Fisher comparando os três grupos experimentais.

N.A.: não avaliado

A análise dos dados mostrou que, com relação à presença de necrose pulpar, não houve diferença estatisticamente significante entre os grupos. 


\section{Figura 4}

\section{Do estudo em dentes de cães}

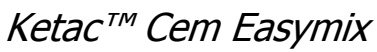

A. 7 dias - Polpa com aspecto normal.

B. 7 dias - Cavidade superficial. Odontoblastos com vacuolização odontoblástica.

C. Maior aumento da Fig. 4B.

D. 70 dias - Polpa preservada, com camada odontoblástica discretamente vacuolada.

E. Maior aumento da Fig. 4D.

F. 70 dias - Polpa normal. Depósito de dentina reacional (DR) nas paredes pulpares.

G. Maior aumento da Fig. 4F.

H. 70 dias - Polpa normal.

I. Maior aumento da Fig. 4H. com odontoblastos vacuolados (setas).

Coloração: H. E e Tricrômio de Mallory

Aumentos originais: $A, C, E, G$ e H: $10 x$

$B$, D e F: $4 x$

I: $40 \mathrm{x}$ 

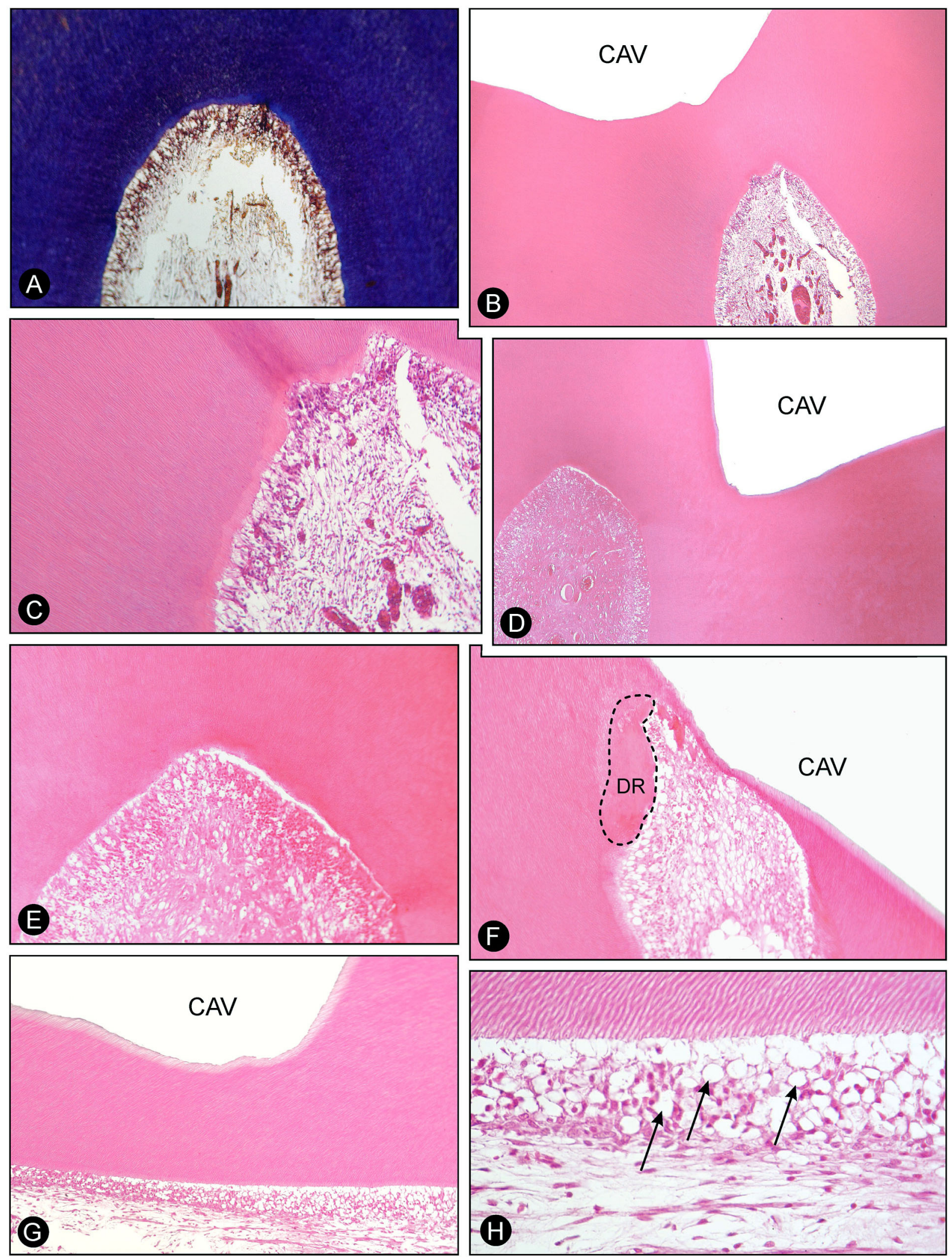


\section{Figura 5}

\section{Do estudo em dentes de cães}

RelyX $X^{T M}$ Unicem

A. 7 dias - Cavidade profunda (linha). Polpa normal.

B. Maior aumento da Fig. 5A.

C. Maior aumento da Fig. 5B.

D. 7 dias - Polpa normal na qual a cavidade era profunda.

E. 70 dias - Polpa normal.

F. Maior aumento da Fig. 5E. com odontoblastos vacuolados (setas).

Coloração: H. E. e Tricrômio de Mallory

Aumentos originais: A e E: $10 x$

B, C, D e F: 40x 


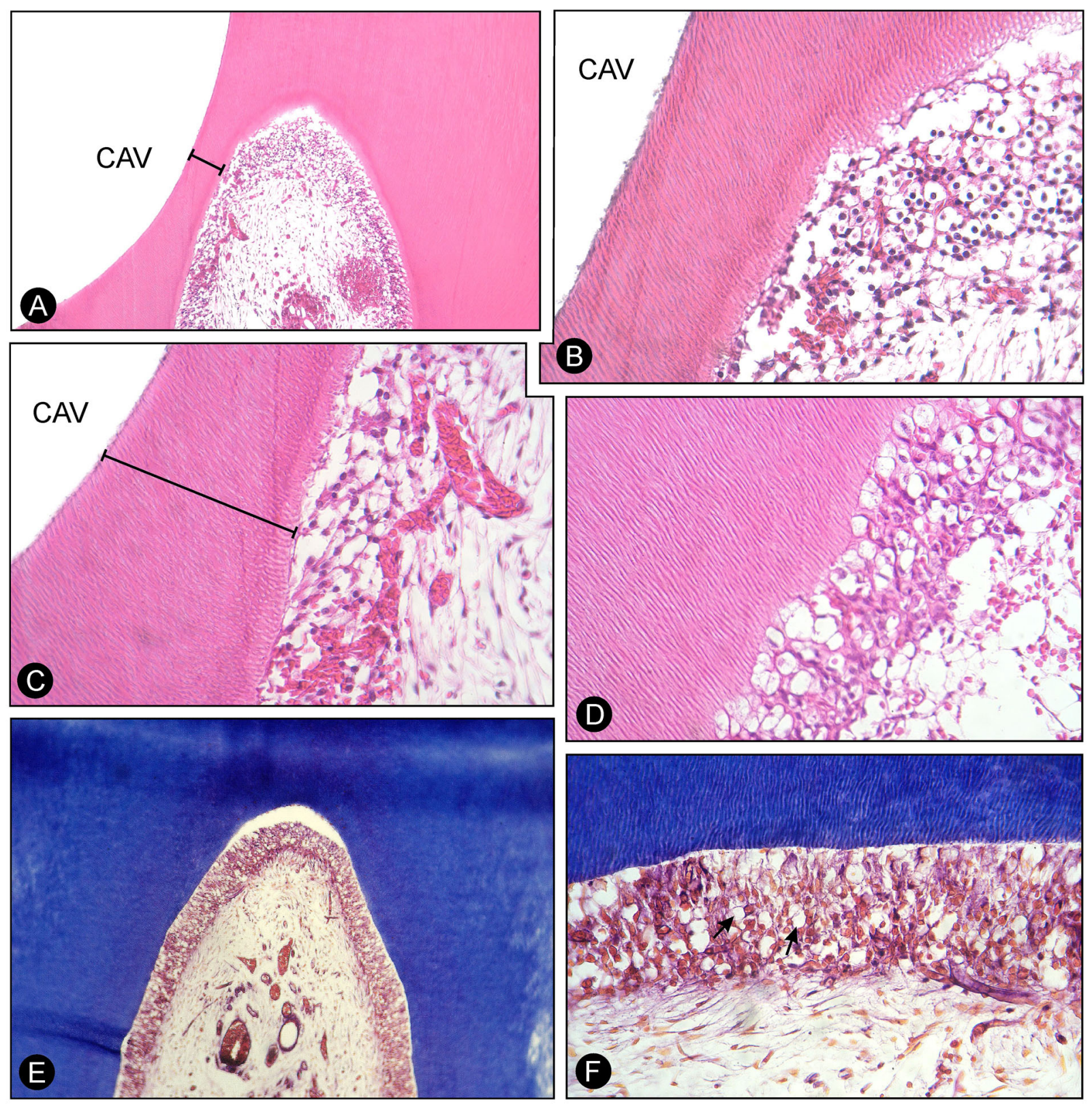




\section{Figura 6}

\section{Do estudo em dentes de cães}

Cimento de óxido de zinco e eugenol

A. 7 dias - Polpa normal com vacuolização odontoblástica.

B. Maior aumento da Fig. 6A.

C. Maior aumento da Fig. 6B.

D. 70 dias - Cavidade profunda (seta) e próxima da polpa que se apresenta normal.

E. Maior aumento da Fig. 6D.

F. Região apical e periapical íntegras com ligamento periodontal.

Coloração: H. E.

Aumentos originais: A e $\mathrm{E}: 4 \mathrm{x}$

B e C: $40 x$

D: $4 x$ 

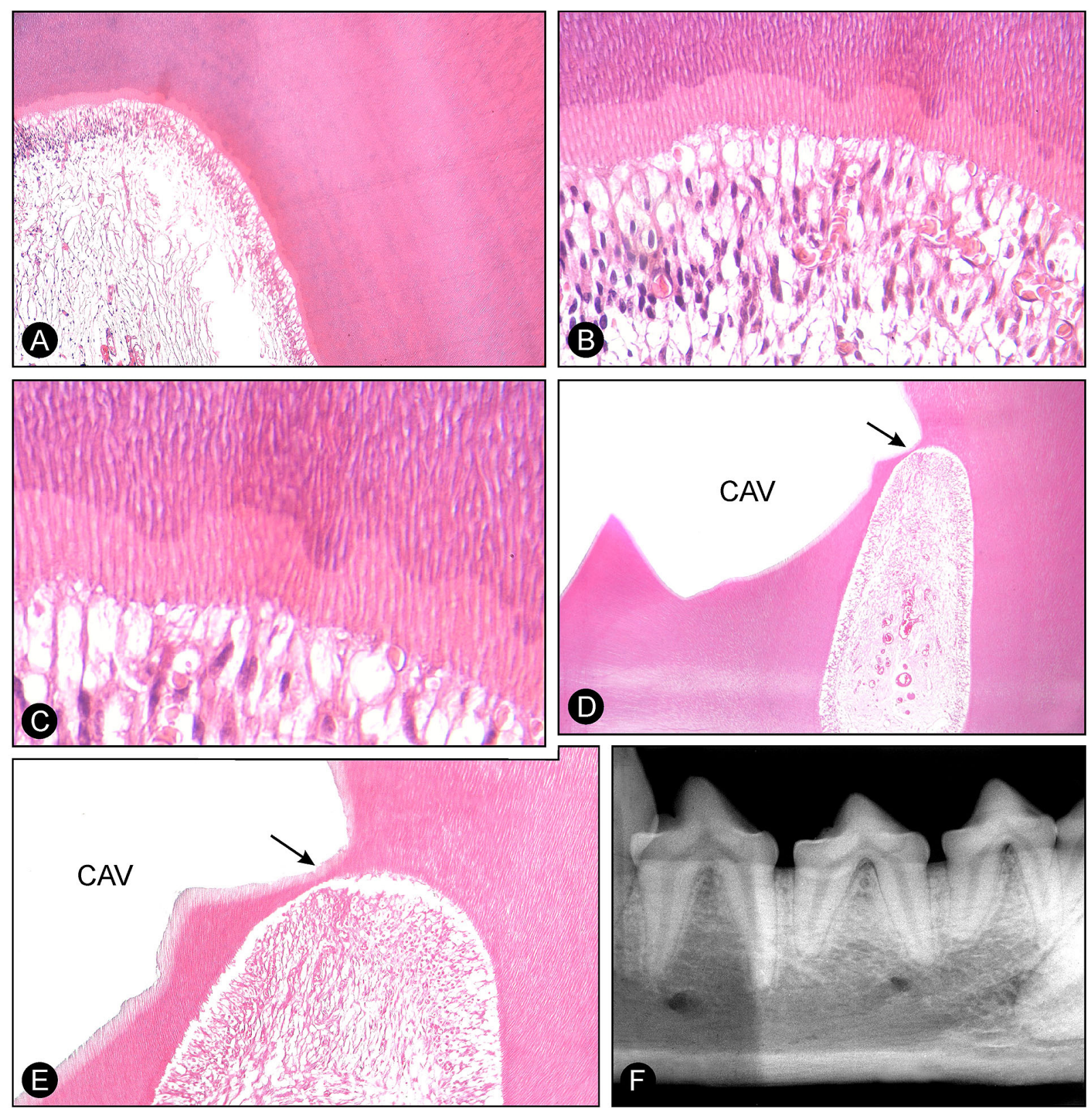


\section{Do estudo radiográfico em dentes de cães}

Os resultados da avaliação radiográfica, realizada por 3 examinadores calibrados (Kappa=0,9636), com relação à integridade da lâmina dura, presença de áreas de rarefação óssea periapical e presença de reabsorções radiculares (interna e externa), nas raízes dos grupos I, II e III (período de 7 dias) e dos grupos IV, V e VI (período de 70 dias) encontram-se nas tabelas 10 e 11.

Tabela 10 - Resultados da avaliação radiográfica aos 7 dias, com relação à integridade da lâmina dura, presença de áreas de rarefação óssea periapical e presença de reabsorções radiculares (interna e externa), nas raízes dos grupos I, II e III. Os resultados encontram-se expressos em número de raízes e porcentagem

\begin{tabular}{|c|c|c|c|c|c|c|c|c|}
\hline \multirow[t]{2}{*}{ Grupos } & \multicolumn{2}{|c|}{$\begin{array}{l}\text { Integridade da } \\
\text { lâmina dura }\end{array}$} & \multicolumn{2}{|c|}{$\begin{array}{c}\text { Rarefação óssea } \\
\text { periapical }\end{array}$} & \multicolumn{2}{|c|}{$\begin{array}{c}\text { Reabsorção } \\
\text { radicular interna }\end{array}$} & \multicolumn{2}{|c|}{$\begin{array}{c}\text { Reabsorção radicular } \\
\text { externa }\end{array}$} \\
\hline & Ausente & Presente & Ausente & Presente & Ausente & Presente & Ausente & Presente \\
\hline \multirow[t]{2}{*}{$\begin{array}{c}\text { Grupo IV } \\
\text { (Ketac Cem } \\
\text { Easymix }{ }^{\circledR} \text { - } \\
7 \text { dias) }\end{array}$} & 0 & 12 & 12 & 0 & 12 & 0 & 12 & 0 \\
\hline & & $100 \%$ & $100 \%$ & & $100 \%$ & & $100 \%$ & \\
\hline \multirow{2}{*}{$\begin{array}{c}\text { Grupo V } \\
\text { (RelyX }^{\mathrm{TM}} \\
\text { Unicem - } 7 \\
\text { dias) }\end{array}$} & 0 & 14 & 14 & 0 & 14 & 0 & 14 & 0 \\
\hline & & $100 \%$ & $100 \%$ & & $100 \%$ & & $100 \%$ & \\
\hline \multirow{3}{*}{$\begin{array}{l}\text { Grupo VI } \\
\text { (Óxido de } \\
\text { zinco e } \\
\text { Eugenol - } 7 \\
\text { dias) }\end{array}$} & 0 & 8 & 8 & 0 & 8 & 0 & 8 & 0 \\
\hline & & & & & & & & \\
\hline & & $100 \%$ & $100 \%$ & & $100 \%$ & & $100 \%$ & \\
\hline
\end{tabular}

Nos 3 grupos estudados (I, II e III), no período experimental de 7 dias, observou-se integridade da lâmina dura, ausência de rarefação óssea periapical e ausência de reabsorção radicular (interna e externa) em todos os espécimes (100\%). 
Tabela 11 - Resultados da avaliação radiográfica aos 70 dias, com relação à integridade da lâmina dura, presença de áreas de rarefação óssea periapical e presença de reabsorções radiculares (interna e externa) nas raízes dos grupos IV, V e VI. Os resultados encontram-se expressos em número de raízes e porcentagem

\begin{tabular}{|c|c|c|c|c|c|c|c|c|}
\hline \multirow[t]{2}{*}{ Grupos } & \multicolumn{2}{|c|}{$\begin{array}{l}\text { Integridade da } \\
\text { lâmina dura }\end{array}$} & \multicolumn{2}{|c|}{$\begin{array}{l}\text { Rarefação óssea } \\
\text { periapical }\end{array}$} & \multicolumn{2}{|c|}{$\begin{array}{l}\text { Reabsorção } \\
\text { radicular interna }\end{array}$} & \multicolumn{2}{|c|}{$\begin{array}{l}\text { Reabsorção } \\
\text { radicular externa }\end{array}$} \\
\hline & Ausente & Presente & Ausente & Presente & Ausente & Presente & Ausente & Presente \\
\hline \multirow[t]{2}{*}{$\begin{array}{c}\text { Grupo IV } \\
\text { (Ketac Cem } \\
\text { Easymix } ® \text { - } \\
70 \text { dias) }\end{array}$} & 4 & 10 & 10 & 4 & 14 & 0 & 14 & 0 \\
\hline & $28,57 \%$ & $71,42 \%$ & $71,42 \%$ & $28,57 \%$ & $100 \%$ & & $100 \%$ & \\
\hline \multirow{2}{*}{$\begin{array}{c}\text { Grupo V } \\
\text { (RelyX }{ }^{\text {TM }} \\
\text { Unicem - } 70 \\
\text { dias) }\end{array}$} & 4 & 12 & 12 & 4 & 16 & 0 & 16 & 0 \\
\hline & $25 \%$ & $75 \%$ & $75 \%$ & $25 \%$ & $100 \%$ & & $100 \%$ & \\
\hline \multirow{3}{*}{$\begin{array}{l}\text { Grupo VI } \\
\text { (Óxido de } \\
\text { zinco e } \\
\text { Eugenol - } \\
70 \text { dias) }\end{array}$} & 0 & 8 & 8 & 0 & 8 & 0 & 8 & 0 \\
\hline & & & & & & & & \\
\hline & & $100 \%$ & $100 \%$ & & $100 \%$ & & $100 \%$ & \\
\hline
\end{tabular}

Nos 3 grupos estudados (IV, V e VI), no período experimental de 70 dias, não foi detectada a presença de reabsorções radiculares (interna e externa) em nenhuma das raízes. No período de 70 dias, observou-se radiograficamente a perda da integridade da lâmina dura em 4 raízes (28,57\%) do grupo IV e em 4 raízes (25\%) do grupo V.

Além disso, nesse período, foram observadas áreas de rarefação óssea periapical apenas nos grupos IV e V. Os resultados da quantificação da área dessas lesões, obtida por meio da mensuração das áreas radiolúcidas em cada raiz utilizando o programa Image J $1.37 \mathrm{v}$ (National Institutes of Health - USA), encontram-se expressos na tabela 12 , em $\mathrm{mm}^{2}$. 
Tabela 12 - Quantificação, em mm², das áreas das rarefações ósseas periapicais, observadas radiograficamente nos grupos IV e $\mathrm{V}$.

\begin{tabular}{ccc}
\hline Raízes & $\begin{array}{c}\text { Grupo IV (Ketac }{ }^{\mathrm{TM}} \text { Cem Easymix } \\
-70 \text { dias) }\end{array}$ & $\begin{array}{c}\text { Grupo V (RelyX } \\
-70 \text { dias }\end{array}$ \\
\hline 1 & 8.808 & 8.427 \\
2 & 5.271 & 3.441 \\
3 & 8.623 & 6.361 \\
4 & 5.275 & 3.447 \\
\hline Média em $\mathrm{mm}^{2}$ & 6.994 & 5.419 \\
\hline
\end{tabular}

Observou-se a presença de lesão periapical em 4 espécimes do grupo IV, com áreas variando de 5.271 a $8.808 \mathrm{~mm}^{2}\left(\right.$ média $\left.=6.994 \mathrm{~mm}^{2}\right)$. No grupo $\mathrm{V}$, também se observou a presença de lesão periapical em 4 espécimes, com áreas variando de 3.441 a $8.427 \mathrm{~mm}^{2}$ (média $\left.=5.419 \mathrm{~mm}^{2}\right)$. 
Discussão 


\section{Discussão}

\section{Dos animais de experimentação e dos materiais utilizados}

Para o presente estudo, foi selecionado como animal experimental o cão, tendo em vista que este animal apresenta um processo de reparo pulpar, apical e periapical semelhante ao humano. Além disso, é de fácil manuseio, sua manutenção em canil é viável economicamente, são animais que resistem à anestesia geral por longos períodos de tempo e por isso, o cão tem sido o modelo animal mais empregado nos trabalhos de pesquisa biológica (Citrome et al., 1979; Nakashima 1994; Katebzadech et al., 1999; Holland et al., 2001; Faraco-Junior e Holland, 2004; Silva et al., 2006).

A seleção dos segundos, terceiros e quartos pré-molares inferiores e segundos e terceiros pré-molares superiores foi baseada no fato desses dentes possuírem semelhança anatômica entre si e apresentarem tecido pulpar de volume semelhante facilitando, assim, as tomadas radiográficas. No arco superior, o quarto pré-molar não foi utilizado pelo fato de possuir três raízes e por ter volume pulpar bem maior que seus homônimos. Não foram utilizados os primeiros pré-molares por esses serem unirradiculares e também porque, segundo Evans e Christensen (1979), por não serem substituídos são considerados como pertencentes à dentição decídua.

Além do cão, utilizou-se também como modelo experimental o camundongo devido à sua fácil acomodação e manuseio, baixo custo e por proporcionar um maior número de animais em cada grupo experimental, possibilitando uma outra forma de análise dos materiais estudados. No presente estudo, foram utilizados camundongos isogênicos, da linhagem Balb/c, uma vez que, por serem animais gerados em laboratório, semelhantes geneticamente, apresentam padrão homogêneo de resposta frente ao mesmo estímulo. Este modelo elimina o inconveniente de testar-se todos os materiais em um mesmo animal, 
possibilitando, assim, o implante de um único tubo de polietileno em cada animal. Como conseqüência, os resultados obtidos com essa metodologia são considerados de grande confiabilidade, visto não haver interferência do fator genético.

Com relação aos materiais avaliados, foram selecionados cimentos recentemente lançados no comércio especializado (Ketac ${ }^{\mathrm{TM}}$ Cem Easymix e RelyX ${ }^{\mathrm{TM}}$ Unicem), rotineiramente aplicados em cavidades profundas, sendo sua biocompatibilidade até então não comprovada. Como a literatura apresenta trabalhos avaliando apenas as propriedades físico-químicas desses cimentos (De Munk et al., 2004; Komine et al., 2004; Goracci et al., 2004; Behr et al., 2004; Balbosh et al., 2005; Kumbuloglu et al., 2005; Lüthy et al., 2005; Piwowarczyk et al., 2005; Burke et al., 2006; Sadek et al., 2006; Naumann et al., 2006; Escribano e de la Macorra, 2006; Goracci et al, 2006; Baldissara et al., 2006; Gerth et al., 2006; de Durão Mauricio et al., 2007; Al-Assaf et al., 2007; Piwowarczyk et al, 2007; Hikita et al., 2007), não comprovando sua biocompatibilidade, optou-se por realizar esse estudo biológico utilizando-os como material protetor indireto em cavidades profundas de dentes de cães e no subcutâneo de camundongos isogênicos.

\section{Dos resultados}

A tolerância tecidual aos cimentos é importante, visto que a dentina e a polpa são consideradas um órgão único (complexo dentina-polpa) devido à íntima relação entre o conteúdo celular dos túbulos dentinários e o tecido pulpar (Mjor, 1984). Enquanto os túbulos fazem parte de $20-39 \%$ da dentina, o fluido dentinário representa cerca de $22 \%$ do volume total da dentina (Mjor, 1984; Trowbridge, 1984). Também, a dentina apresenta uma média de 65.000 - 75.000 túbulos por $\mathrm{mm}^{2}$ nas proximidades da polpa, 30 a 35.000 na porção média e 10 a 25.000 túbulos na periferia. Nas proximidades da polpa, além de mais numerosos, o diâmetro dos túbulos é maior, variando entrem 2,5 e 3,0 micrometros, enquanto na periferia o mesmo atinge diâmetro menor que 1,0 micrometro (Garberoglio e 
Branstrom, 1976; Mjor, 1984). Outro fator relevante é o fato de a dentina apresentar $1 \%$ de permeabilidade próximo à junção amelodentinária, 7,6\% na porção mediana e 22\% próximo à polpa (Pashley, 1985; Pashley et al., 1987).

Desta forma, a passagem de substâncias através da dentina, atingindo a polpa e ocasionando alterações patológicas, depende do tamanho da molécula, dos componentes do produto utilizado, da área disponível para difusão, da patência dos túbulos dentinários, assim como da espessura do remanescente dentinário. Segundo Stanley (1994), a maior parte dos materiais utilizados para cimentação é irritante ao tecido pulpar, principalmente quando o remanescente dentinário é inferior a 0,5mm. Pameijer et al. (1991) relataram que a espessura de dentina remanescente igual ou superior a $1 \mathrm{~mm}$ pode proteger o tecido pulpar de efeitos citotóxicos de cimentos como o fosfato de zinco e o cimento de ionômero de vidro modificado por resina durante o procedimento de cimentação. Este fato pôde ser observado no presente estudo, onde os materiais avaliados apresentaram comportamentos diferentes, quando colocados sobre a dentina e quando colocados sobre áreas de microexposição pulpar.

A reação pulpar ao preparo cavitário pode variar de uma resposta inflamatória discreta associada a uma leve desorganização tecidual, até uma necrose pulpar parcial ou a um completo colapso pulpar. Vários fatores como a secagem da dentina exposta, o calor gerado pelo contínuo corte durante o preparo cavitário ou a inadequada refrigeração, entre outros, têm sido relatados como responsáveis por danos pulpares (Zach e Cohen, 1962; Goodis et al., 1988; Pashley, 1996; Murray et al., 2000; Murray et al., 2001; Wisithphrom et al., 2006).

No presente estudo, em alguns espécimes dos grupos experimentais em que se utilizou o cão, apesar da polpa apresentar-se com características normais, foi notada a presença de vacúolos na camada odontoblástica (4 espécimes do grupo I, 8 espécimes do grupo III e 10 espécimes do grupo IV), alterações reticulares (4 espécimes do grupo III) e intensa congestão vascular (4 espécimes do grupo III). Como a polpa apresentou-se normal em todos os espécimes dos grupos I e II, em 4 espécimes do grupo III, em 10 espécimes do 
grupo IV, em 12 espécimes do grupo V e em 6 espécimes do grupo VI, sugere-se que essas alterações estejam relacionadas ao preparo cavitário, mas principalmente aos procedimentos de obtenção da peça e fixação da polpa.

Entretanto, Costa et al. (2006) relataram resposta pulpar inflamatória variando de discreta a moderada e desorganização pulpar nos grupos experimentais, nos quais utilizou cimentos resinosos (RelyX ${ }^{\mathrm{TM}}$ Unicem - 3M ESPE e Variolink II - Ivoclair Vivadent) para cimentação de inlays, em dentes de humanos. Por outro lado, não foram observadas alterações pulpares no grupo controle, no qual as paredes axiais foram forradas com cimento de hidróxido de cálcio, previamente à cimentação. Esses autores sugeriram que a interação dos materiais experimentais com o complexo dentino-pulpar, ao invés do preparo cavitário, ocasionou os efeitos irritantes iniciais à polpa. No presente trabalho, nos períodos iniciais dos grupos experimentais em que se utilizou o cão (7dias), observou-se a presença de focos hemorrágicos apenas no grupo I (Ketac ${ }^{\top M}$ Cem Easymix), e de áreas de ulceração e inflamação no grupo III (Cimento de óxido de zinco e eugenol), enquanto que o grupo II (RelyX ${ }^{\mathrm{TM}}$ Unicem) não apresentou alterações pulpares. As respostas teciduais obtidas após implante subcutâneo nos camundongos isogênicos mostraram que o RelyX ${ }^{\mathrm{TM}}$ Unicem apresentou resposta semelhante ao grupo controle, enquanto que o $\mathrm{Ketac}^{\mathrm{TM}} \mathrm{Cem}$ Easymix mostrou resposta inflamatória exacerbada em todos os períodos. De acordo com Costa et al. (2006) essas alterações seriam decorrentes da citotoxicidade dos materiais testados e não do preparo cavitário.

A presença de deposição de dentina reacional em alguns espécimes dos grupos IV (Ketac $^{\mathrm{TM}}$ Cem Easymix - 70 dias), V (RelyX ${ }^{\mathrm{TM}}$ Unicem - 70 dias) e VI (Cimento de Óxido de zinco e eugenol - 70 dias) pode ser explicada pelo fato de que, após leves agressões à polpa, não ocorre a morte de odontoblastos, os quais sobrevivem e são estimulados a sintetizar e secretar uma matriz de dentina reacional. Os estímulos aos odontoblastos inativos levarão a uma secreção local de nova matriz na interface dentina-polpa e, possivelmente, na dentina 
intratubular, identificados microscopicamente como esclerose dentinária ocasionando uma diminuição da permeabilidade dentinária (Mjör, 1985). Por outro lado, em agressões de grande intensidade, vários odontoblastos primários morrerão e células-tronco pulpares da camada sub-odontoblástica poderão se diferenciar para dar início a uma nova geração de células tipo odontoblastos, responsáveis pela deposição de um tipo específico de dentina terciária denominada dentina reparadora (Lesot et al., 1994; Smith et al., 1995; Smith et al., 2002).

Duque et al. (2006) relataram que a distância de difusão de qualquer molécula bioativa liberada através dos túbulos dentinários também é uma consideração em termos dos seus efeitos estimulatórios nos odontoblastos e células pulpares. Assim, a espessura de dentina remanescente é importante e, portanto, a difusão para interagir com essas células é favorecida em cavidades mais profundas (Murray et al., 2001; Duque et al., 2006). Neste trabalho, nos espécimes dos grupos IV (Ketac ${ }^{\mathrm{TM}}$ Cem Easymix - 70 dias), V (RelyX ${ }^{\mathrm{TM}}$ Unicem - 70 dias) e VI (Cimento de óxido de zinco e eugenol - 70 dias) em que houve microexposição, a polpa apresentou alterações mais severas variando desde uma inflamação até casos de necrose pulpar com presença de reação periapical. Esses resultados evidenciam que os materiais, em contato direto com a polpa, desencadearam reações pulpares intensas e, para que ocorram respostas pulpares satisfatórias, deve haver uma espessura de dentina remanescente suficiente para proteger a polpa dos efeitos irritantes desses materiais. Murray et al. (2002) relataram que, para que ocorra deposição de dentina reacional, a espessura de dentina remanescente deve estar entre $0,5-0,25 \mathrm{~mm}$.

Além disso, o RelyX ${ }^{\mathrm{TM}}$ Unicem (3M ESPE) apresenta cerca de $2 \%$ de $\mathrm{Ca}(\mathrm{OH})_{2}$ em sua composição, o que pode ter contribuído na indução de formação de dentina reacional no grupo em que esse material foi aplicado (Grupo V).

Deve ser ressaltado que, em função da ausência de trabalhos publicados empregando os mesmo materiais, em especial o $\mathrm{Ketac}^{\mathrm{TM}}$ Cem Easymix (3M ESPE), em condições 
semelhantes às do presente estudo, a comparação direta dos resultados por nós obtidos com a literatura específica torna-se impossibilitada.

Nos grupos em que foi utilizado o cimento de óxido de zinco e eugenol não ocorreram alterações pulpares, exceto em 4 espécimes do grupo III (7 dias) e em 2 espécimes do grupo VI (70 dias), nos quais pôde ser observada microexposição pulpar. Nosso trabalho está de acordo com Murray et al. (2001) que relataram que o cimento de óxido de zinco e eugenol, em proteções pulpares indiretas, não desencadeia reações pulpares intensas.

Entretanto, sabe-se que o eugenol, pode ocasionar danos aos tecidos em função de sua citotoxicidade, com degeneração do tecido mucoso e morte de fibroblastos, além de dermatite de contato e reação alérgica (Barkin et al., 1984; Sarrami et al., 2002). O eugenol, na dependência da concentração utilizada, é capaz de inibir a respiração, divisão celular e até causar a morte das células (Hume, 1986; Markowitz, 1992). Esse fato pode explicar a reação tecidual desfavorável observada nos casos de microexposição pulpar, com o uso desse material.

O RelyX ${ }^{\mathrm{TM}}$ Unicem contém um novo metacrilato modificado por ácido fosfórico multifuncional na sua composição, que permite um auto-condicionamento da estrutura dental, sem a necessidade de um passo isolado de condicionamento ácido. Um novo sistema iniciador permite um alto grau de conversão de polímero, resultando em baixa solubilidade e biocompatibilidade (Souza et al., 2006). Como relatado pelo fabricante, durante a reação de presa, que estabelece a adesão à estrutura dentária, o pH do material eleva-se a um nível neutro. Pode-se dizer que três características do RelyX $\mathrm{X}^{\mathrm{TM}}$ Unicem podem prevenir a hidrólise e a liberação de componentes para difundir através dos túbulos dentinários: 1- reação química com a estrutura dental; 2- baixa solubilidade; e 3- mecanismo auto-neutralizante durante a reação de presa (Costa et al., 2006). As reações pulpares satisfatórias desse cimento em cavidades profundas, sem exposição pulpar, puderam ser comprovadas no presente estudo, já que a polpa apresentou-se com características normais em ambos os 
períodos, estando alterada apenas nos casos em que houve exposição pulpar e contato direto do material com o tecido pulpar. Souza et al. (2006) avaliaram a resposta tecidual de cimentos ionoméricos modificados por resina e observaram que, inicialmente, esses cimentos apresentaram uma inflamação moderada, que diminuiu com o passar do tempo, podendo, posteriormente, ser observado reparo tecidual. As mesmas características puderam ser observadas no presente estudo, nos grupos em que se utilizou o RelyX ${ }^{\mathrm{TM}}$ Unicem no tecido conjuntivo subcutâneo de camundongos.

No entanto, não se observou a presença de microrganismos em nenhum dos grupos analisados nas colorações utilizadas. A ausência de bactérias pode ser atribuída à atividade antibacteriana do flúor liberado pelos materiais ionoméricos e do eugenol liberado pelo cimento de óxido de zinco e eugenol (Tjan et al., 1997; Cox et al., 1998; Hebling et al., 1999; Kitsano et al., 2000). Além disso, Piwowarczyk et al. (2005) demonstraram que o RelyX ${ }^{\mathrm{TM}}$ Unicem apresenta baixo grau de microinfiltração, tanto em esmalte quanto em dentina.

Os resultados da análise microscópica em dentes de cães evidenciaram que, quando empregados sobre a dentina, ambos os cimentos não ocasionam reações pulpares insatisfatórias podendo, portanto, ser indicados como materiais para cimentação. No entanto, quando colocados diretamente sobre o tecido pulpar, desencadearam reação inflamatória intensa, com necrose pulpar e desenvolvimento de reação periapical, ou seja, não apresentam biocompatibilidade. Esses resultados foram também confirmados no estudo radiográfico, onde se observou lesões periapicais com média de $6.994 \mathrm{~mm}^{2}$ no grupo IV $\left(\right.$ Ketac $^{\mathrm{TM}}$ Cem Easymix - 70 dias) e $5.419 \mathrm{~mm}^{2}$ no grupo $\mathrm{V}$ (RelyX ${ }^{\mathrm{TM}}$ Unicem - 70 dias), nos casos onde houve microexposição pulpar e recobrimento com os cimentos (Ketac ${ }^{\mathrm{TM}}$ Cem Easymix e RelyX ${ }^{\mathrm{TM}}$ Unicem). No tecido conjuntivo subcutâneo de camundongos, o $\mathrm{Ketac}^{\mathrm{TM}}$ Cem Easymix apresentou resposta inflamatória evidente em todos os períodos, sem indícios de reparo, o que comprova que este material não apresenta biocompatibilidade quando em contato com o tecido conjuntivo. Já o RelyX $\mathrm{X}^{\mathrm{TM}}$ Unicem apresentou resposta inflamatória 
crônica discreta em todos os períodos analisados. Aos 63 dias, o tecido conjuntivo fibroso periférico apresentou-se normal, ou seja, o reparo tecidual aconteceu independentemente da presença do material.

De acordo com as recomendações dos fabricantes, previamente ao uso dos adesivos dentinários em cavidades profundas com exposição pulpar, deve-se empregar o hidróxido de cálcio, o que não é seguido por muitos clínicos. Nossos resultados reafirmam as instruções dos fabricantes dos agentes cimentantes do RelyX ${ }^{\mathrm{TM}}$ Unicem e Ketac ${ }^{\mathrm{TM}}$ Cem Easymix, onde indica-se o uso do hidróxido de cálcio em casos de cavidades profundas, previamente à cimentação. 


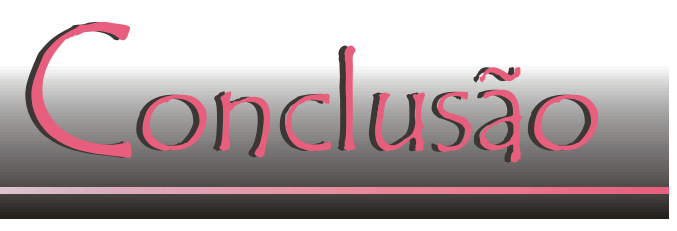




\section{Conclusão}

Com base nas metodologias empregadas e nos resultados obtidos, pudemos concluir que:

- Os cimentos RelyX ${ }^{T M}$ Unicem e Ketac ${ }^{T M}$ Cem Easymix podem ser empregados na dentina de cavidades profundas, sem exposição pulpar. No entanto, quando em contato com o tecido conjuntivo subcutâneo e com o tecido pulpar em microexposições houve fenômenos reacionais insatisfatórios. 
Referênciąs 


\section{RefERÊNCIAS ${ }^{1}$}

1. 3M ESPE. Wissenschaftliches Produktdossier RelyX Unicem. 3M ESPE AG, 82229 Seefeld, Germany.

2. Al-Assaf K, Chakmakchi M, Palaghias G, Karanika-Kouma A, Eliades G. Interfacial characteristics of adhesive luting resins and composites with dentine. Dent Mater 2007 Jul;23(7):829-39.

3. Balbosh A, Ludwig $K$, Kern M. Comparison of titanium dowel retention using four different luting agents. J Prosthet Dent. 2005 Sep;94(3):227-33.

4. Baldissara $P$, Valandro LF, Monaco C, Ferrari M, Bottino MA, Scotti R. Fatigue resistance of the bond of a glass-infiltrated alumina ceramic to human dentin. J Adhes Dent 2006 Apr;8(2):97-104.

5. Barkin ME, Boyd JP, Cohen S. Acute allergic reaction to eugenol. Oral Surg Oral Med Oral Pathol 1984 Apr;57(4):441-2.

6. Behr M, Rosentritt M, Regnet T, Lang R, Handel G. Marginal adaptation in dentin of a self-adhesive universal resin cement compared with well-tried systems. Dent Mater 2004;20:191-197.

7. Bottino MA, Brunetti RF. Manual de prótese parcial fixa. São Paulo: Ed. Santos; 1986.

8. Bouillaguet S, Wataha JC, Hanks CT, Ciucchi B, Holz J. In vitro cytotoxicity and dentin permeability of HEMA. J Endod 1996 May;22(5):244-8.

9. Burke FJ, Fleming GJ, Abbas G, Richter B. Effectiveness of a self-adhesive resin luting system on fracture resistance of teeth restored with dentin-bonded crowns. Eur J Prosthodont Restor Dent 2006 Dec;14(4):185-8.

10. Chan WD, Yang L, Wan W, Rizkalla AS. Fluoride release from dental cements and composites: a mechanistic study. Dent Mater 2006 Apr;22(4):366-73.

11. Christensen GJ. Cimentos, agentes de forramento e bases em prótese fixa. In: MALONE WFP; KOTH DL. Teoria e prática da prótese fixa de Tylman. $8^{a}$ ed. São Paulo: Artes médicas; 1991. p. 381-92.

12. Citrome GP, Kaminski EJ, Heuer MA. A comparative study of tooth apexification in the dog. J Endod 1979 Oct;5(10):290-7.

13. Cooper IR. The response of the human dental pulp to glass-ionomer cements. Int Endod J 1980;13:76-88.

\footnotetext{
${ }^{1}$ Normas internas do Programa de Pós-Graduação em Odonpediatria das FORP-USP (2003), de acordo com o International Comitte of Medicals Journals Editors. Uniform Requirementss for manuscripts submitted do Medical Journal, 1997. Disponível em: http://www.mja.com.au/public/information/uniform.html. Acesso em 2 de outubro de 2005.
} 
14. Cordeiro RCL, Leonardo MR, Silva LAB, Cerri PS. Desenvolvimento de um dispositivo para padronização de tomadas radiográficas em cães. Rev. Pós-Grad. Bauru $1995 ; 2: 138-40$.

15. Costa CA, Lopes do Nascimento AB, Teixeira HM, Fontana UF. Response of human pulps capped with a self-etching adhesive system. Dent Mater 2001 May;17(3):230-40.

16. Costa $C A$, Teixeira HM, do Nascimento $A B$, Hebling J. Biocompatibility of an adhesive system and 2-hydroxyethylmethacrylate. ASDC J Dent Child 1999 Sep-Oct;66(5):337$42,294$.

17. Costa CAS, Giro EMA, Nascimento AB, Teixeira HM, Hebling J. Short-term evaluation of the pulpo-dentin complex response to a resin-modified glass-ionomer cement and a bonding agent applied in deep cavities. Dent Mater 2003;19:739-746.

18. Costa CAS, Hebling J, Randall RC. Human pulp response to resin cements used to bond inlay restorations. Dent Mater 2006 Oct;22(10):954-62.

19. Costa CAS, Teixeira HM, Lopes do Nascimento AB, Hebling J. Biocompatibility of resinbased dental materials applied as liners in deep cavities prepared in human teeth. J Biomed Mater Res B Appl Biomater 2007 Apr;81(1):175-84.

20. Cox CF, Hafez AA, Akimoto N, Otsuki N, Suzuki S, Tarim B. Biocompatibility of primer, adhesive and resin composite systems on nonexposed and exposed pulps of non human primate teeth. Am J Dent 1998;11(special issue):S55-63.

21. De Durão Maurício PJ, González-López S, Aguilar-Mendoza JA, Félix S, GonzálezRodríguez MP. Comparison of regional bond strength in root thirds among fiberreinforced posts luted with different cements. J Biomed Mater Res B Appl Biomater. 2007 Mar 23; [Epub ahead of print].

22. De Munk J, Vargas M, Van Landuyt K, Hikita K, Lambrechts P, Van Meerbeek B. Bonding of an auto-adhesive luting material to enamel and dentin. Dent Mater 2004;20:963-971.

23. Donly $\mathrm{KJ}$, Nelson JJ. Fluoride release of restorative materials exposed to a fluoridated dentifrice. ASDC J Dent Child 1997;64:249-250.

24. Duque C, Hebling J, Smith AJ, Giro EM, Oliveira MF, de Souza Costa CA. Reactionary dentinogenesis after applying restorative materials and bioactive dentin matrix molecules as liners in deep cavities prepared in nonhuman primate teeth. J Oral Rehabil 2006 Jun;33(6):452-61.

25. Escribano N, de la Macorra JC. Microtensile bond strength of self-adhesive luting cements to ceramic. J Adhes Dent 2006 Oct;8(5):337-41.

26. Evans HE, Christensen G. The digestive apparatus and abdomen. In: Miller's anatomy of the dog. Philadelphia: Saunders; 1979. p.411-506.

27. Faraco Junior IM, Holland R. Faraco Junior IM, Holland R. Histomorphological response of dogs' dental pulp capped with white mineral trioxide aggregate. Braz Dent J 2004;15(2):104-8. 
28. Felton DA, Cox CF, Odom M, Kanoy BE. Pulpal response to chemically cured and experimental light-cured glass-ionomer cavity liners. J Prosthe Dent 1991;65:704-712.

29. Forsten L. Fluoride release and uptake by glass ionomers and related materials and its clinical effect. Biomaterials 1998;19:503-508.

30. Forsten L. Fluoride release from a glass ionomer cement. Scand J Dent 1977;85:503504.

31. Garberoglio R, Branstrom M. Scanning electron microscopy investigation of human dentinal tubules. Arch Oral Biol 1976;21:355-62.

32. Gerth HU, Dammaschke T, Züchner H, Schäfer E. Chemical analysis and bonding reaction of RelyX Unicem and Bifix composites--a comparative study. Dent Mater 2006 Oct;22(10):934-41.

33. Gerzina TM, Hume WR. Diffusion of monomers from bonding resin-resin composite combinations through dentine in vitro. J Dent 1996 Jan-Mar;24(1-2):125-8.

34. Gonzalez CA. Aplicaciones clínicas del cemento de ionômero vítreo. Ver Assoc Odontol Argent 1993;81:71-78.

35. Goodis $\mathrm{HE}$, Schein $\mathrm{B}$, Stauffer $\mathrm{P}$. Temperature changes measured in vivo at the dentinoenamel junction and pulpodentin junction during cavity preparation in the Macaca fascicularis monkey. J Endod 1988 Jul;14(7):336-9.

36. Goracci C, Cury AH, Cantoro A, Papacchini F, Tay FR, Ferrari M. Microtensile bond strength and interfacial properties of self-etching and self-adhesive resin cements used to lute composite onlays under different seating forces. J Adhes Dent 2006 Oct;8(5):327-35.

37. Goracci C, Tavares AU, Fabianelli A, Monticelli F, Raffaelli O, Cardoso PC, Tay F, Ferrari $M$. The adhesion between fiber posts and root canal walls: comparison between microtensile and push-out bond strength measurements. Eur J Oral Sciences 2004;112:353-361.

38. Hebling J, Giro EM, Costa CA. Human pulp response after an adhesive system application in deep cavities. J Dent 1999;27:557-64.

39. Hikita K, Van Meerbeek B, De Munck J, Ikeda T, Van Landuyt K, Maida T, Lambrechts $P$, Peumans $M$. Bonding effectiveness of adhesive luting agents to enamel and dentin. Dent Mater 2007 Jan;23(1):71-80.

40. Hiraishi N, Kitasako Y, Nikaido T, Foxton RM, Tagami J, Nomura S. Acidity of conventional luting cements and their diffusion through bovine dentine. Int Endod J 2003 Sep;36(9):622-8.

41. Holland R, de Souza V, Murata SS, Nery MJ, Bernabé PF, Otoboni Filho JA, Dezan Júnior $\mathrm{E}$. Healing process of dog dental pulp after pulpotomy and pulp covering with mineral trioxide aggregate or Portland cement. Braz Dent J 2001;12(2):109-13. 
42. Hosoda H, Inokosh S, Shimada $Y$, Harnirattisai C, Otsuki M. Pulpal response to a new light-cured composite placed in etched glass-ionomer lined cavities. Oper Dent 1991; $16: 122-129$.

43. Hume WR. The pharmacologic and toxicological properties of zinc oxide-eugenol. J Am Dent Assoc 1986 Nov;113(5):789-91.

44. Katebzadeh N, Hupp J, Trope M. Histological periapical repair after obturation of infected root canals in dogs. J Endod 1999 May;25(5):364-8.

45. Kilpatrick NM. Glass ionomer cements: their application in children. Part 1. Dent Update 1996;23:236-238.

46. Kitsano $\mathrm{Y}$, Nakajima $\mathrm{M}$, Pereira PN, et al. Monkey pulpal response and microtensile strength beneath a one-application resin bonding system in vivo. J Dent 2000;28:193-8.

47. Komine F, Tomic M, Gerds T, Strub JR. Influence of different adhesive resin cements on the fracture strength of aluminum oxide ceramic posterior crowns. J Prothet Dent 2004;92:359-64.

48. Kumbuloglu O, Lassila LVJ, User A, Toksavul S, Vallittu PK. Shear bond strength of composite resin cements to lithium disilicate ceramics. J Oral Rehab 2005;32:128-133.

49. Lesot H, Smith AJ, Tziafas D, Bègüe-Kirn C, Cassidy N, Ruch JV. Biologically active molecules and dental tissue repair: a comparative review of reactionary and reparative dentinogenesis with the induction of odontoblast differentiation in vitro. Cells Mater 1994;4:199-218.

50. Li ZC, White SN. Mechanical properties of dental luting cements. J Prosthet Dent 1999 May;81(5):597-609.

51. Lüthy $\mathrm{H}$, Loeffel $\mathrm{O}$, Hammerle CHF. Effect of thermocycling on bond strength of luting cements to zirconia ceramic. Dent Mater 2005;xx:1-6.

52. Mak YF, Lai SC, Cheung GS, Chan AW, Tay FR, Pashley DH. Micro-tensile bond testing of resin cements to dentin and an indirect resin composite. Dent Mater 2002;18:60921.

53. Marinelli CB, Donly KJ, Wefel JS, Jakobsen JR, Denehy GE. An in vitro comparison of 3 fluoride regimens on enamel remineralization. Caries Res 1997;31:418-422.

54. Markowitz K, Moynihan M, Liu M, Kim S. Biologic properties of eugenol and zinc oxideeugenol. A clinically oriented review. Oral Surg Oral Med Oral Pathol 1992 Jun;73(6):729-37.

55. Massara MLA, Diniz APV, Souki BQ, Noronha JC. A importância do selamento provisório de lesões cavitadas na fase de adequação da criança ao tratamento odontológico. Rev CROMG 1997;3:114-121.

56. McLean JW. 26a Jornadas Internacionales de la Associación Odontológica Argentina. Buenos Aires, Argentina. Noviembre. 
57. McLean JW. Alternatives to amalgam. Br Dent J 1984;157:432-433.

58. Menezes JP, Rosenblatt A, Medeiros E. Clinical evaluation of atraumatic restorations in primary molars: a comparison between 2 glass ionomer cements. J Dent Child (Chic) 2006 May-Aug;73(2):91-7.

59. Mjör IA. Dentin-predentin complex and its permeability: physiologic overview. J Dent Res 1985;64:621-627 (special issue).

60. Mjör IA. The morphology of dentin and dentinogenesis. In: Linde A. Boca Raton, Fla:CRC Press, 1984.

61. Mondelli J. Proteção do complexo dentinopulpar. Artes Médicas: São Paulo; 1998.

62. Mount G. Cimentos de ionômero de vidro: passado, presente e futuro. CECAD News. Bauru; 1995. v.3, n.2, p. 19.

63. Mount GJ. A color atlas of glass ionômero cement, $2^{\text {nd }}$ ed. London:Martin Dunitz; 1994.

64. Murray PE, About I, Franquin JC, Remusat M, Smith AJ. Restorative pulpal and repair responses. J Am Dent Assoc 2001 Apr;132(4):482-91.

65. Murray PE, About I, Lumley PJ, Franquin JC, Remusat M, Smith AJ. Cavity remaining dentin thickness and pulpal activity. Am J Dent 2002 Feb;15(1):41-6.

66. Murray PE, Hafez AA, Smith AJ, Cox CF. Bacterial microleakage and pulp inflammation associated with various restorative materials. Dent Mater 2002 Sep;18(6):470-8.

67. Murray PE, Lumley PJ, Ross HF, Smith AJ. Tooth slice organ culture for cytotoxicity assessment of dental materials. Biomaterials 2000;21:1711-21.

68. Nakashima M. Induction of dentine in amputated pulp of dogs by recombinant human bone morphogenetic proteins-2 and -4 with collagen matrix. Arch Oral Biol 1994 Dec;39(12):1085-9.

69. Naumann M, Preuss A, Frankenberger R. Load capability of excessively flared teeth restored with fiber-reinforced composite posts and all-ceramic crowns. Oper Dent 2006 Nov-Dec;31(6):699-704.

70. Navarro MFL, Pascotto RC. Cimentos de ionômero de vidro - aplicações clínicas em Odontologia. São Paulo: Artes Médicas; 1998. 179p.

71. Norman RD, Swartz ML, Phillips RW, Raibley JW. Direct pH determination of setting cements. 2- The effects of prolonged storage time, powder-liquid ratio, temperature and dentin. J Dent Res 1966;45:1214-9.

72. Norman RD, Swartz ML, Phillips RW, Virmani R. A comparison of the intraoral disintegration of three dental cements. JADA 1969;78:777-82.

73. Pameijer $\mathrm{CH}$, Stanley HR, Ecker G. Biocompatibility of a glass ionomer luting agent. 2 . Crown cementation. Am J Dent 1991 Jun;4(3):134-41. 
74. Pameijer $\mathrm{CH}$, Wendt Jr SL. Microleakage of "surface-sealing" materials. Amer J Dent 1995;8:43-6.

75. Pashley DH, Andringa HJ, Derkson GD, Derkson ME, Kalathoor SR. Regional variability in the permeability of human dentine. Arch Oral BIol 1987;32:519-23.

76. Pashley DH. Dentin - predentin complex and its permeability: physiologic overview. J Dent Res 1985;64:613-20.

77. Pashley DH. Dynamics of the pulpo-dentin complex. Crit Rev Oral Biol Med 1996;7(2):104-33.

78. Phillips RW et al. Zinc oxide and eugenol cements for permanent cementation. J Prosthet Dent 1968;19:144-50.

79. Phillips RW, Swartz ML, Lund MS, Moore BK, Vickery J. In vivo disintegration of luting cements. J Am Dent Assoc 1987;114:489-92.

80. Piwowarczyk A, Bender R, Ottl P, Lauer HC. Long-term bond between dualpolymerizing cementing agents and human hard dental tissue. Dent Mater 2007 Feb;23(2):211-7.

81. Piwowarczyk A, Lauer HC, Sorensen JA. In vitro shear bond strength of cementing agents to fixed prosthodontic restorative materials. J Prosthet Dent 2004 Sep;92(3):265-73.

82. Piwowarczyk A, Lauer HC, Sorensen JA. Microleakage of various cementing agents for full cast crowns. Dent Mat 2005;21:445-453.

83. Piwowarczyk A, Ottl P, Lauer HC. Laboratory strength of glass ionomer and zinc phosphate cements. J Prosthodont 2001 Sep;10(3):140-7.

84. Plant CG, Browne RM, Knibbs PJ, Britton AS, Sorahen T. Pulpal effects of glass ionômero cements. Int Endod J 1984;17:51-59.

85. Rosenstiel SF, Land MF, Crispin BJl. Dental luting agents: a review of the current literature. J Prosthet Dent 1998;80:280-301.

86. Sadek FT, Goracci C, Monticelli F, Grandini S, Cury AH, Tay F, Ferrari M. Immediate and 24-hour evaluation of the interfacial strengths of fiber posts. J Endod. 2006 Dec;32(12):1174-7.

87. Sarrami N, Pemberton MN, Thornhill MH, Theaker ED. Adverse reactions associated with the use of eugenol in dentistry. Br Dent J 2002 Sep 14;193(5):257-9.

88. Shillinburg HT. Fundamentos de prótese fixa. Quintessence Publishing Co. Inc.; 1986.

89. Shimada Y. Pulpal response to various dentin conditioning agents. Japan J Conserv Dent 1992;35:69-100. 
90. Silva, LAB, Leonardo, MR, Nelson-Filho P, Medeiros AS, Rossi MA. Pulp response of anionic lyophilized colagen matrix with or without hydroxyapatite after pulpotomy in dogs's teeth. Mat Res 2006. In Press.

91. Simmons J. Postcementation sensitivity associated with the anhidrous form of glassionomer luting cements: a theory. Texas Dent 1988;10:7-8.

92. Smith AJ, Cassidy N, Perry $\mathrm{H}$, Bègüe-Kirn C, Ruch JV, Lesot H. Reactionary dentinogenesis. Int J Dev Biol 1995;39:273-280.

93. Smith AJ, Murray PE, Lumley PJ. Preserving the vital pulp in operative dentistry: a biological approach. Dent Update 2002;29:64-69.

94. Smith DC, Ruse ND. Acidity of glass ionômero cements during setting and its realtion to pulp sensivity. JADA 1986;112:654-7.

95. Smith DC. A review of zinc polycarboxylate cements. J Can Dent Assoc 1971;37:1-8.

96. Souza PP, Aranha AM, Hebling J, Giro EM, Costa CA. $n$ vitro cytotoxicity and in vivo biocompatibility of contemporary resin-modified glass-ionomer cements. Dent Mater 2006 Sep;22(9):838-44.

97. Souza-Gugelmin MCM, Lima SNM, Lima CDL, Jacobovitz M, Ito iY. Biossegurança: controle de infecção na Odontologia. In: Leonardo, MR. Endodontia: tratamento de canais radiculares: princípios técnicos e biológicos. São Paulo: Artes Médicas;2005. p.365-406.

98. Stanley HR. Dental iatrogenisis. Int Dent J 1994;44:3-18.

99. Stanley HR. Pulpal responses to ionômero cements - biological characteristics. JADA 1990;120:25-29.

100. Tay FR, Gwinnett AJ, Pang KM, Wei SH. Structural evidence of a sealed tissue interface with a total-etch wet-bonding technique in vivo. J Dent Res 1994 Mar;73(3):629-36.

101. Tjan $A H$, Tan $D E$, Sun JC, Tjan AH. Marginal leakage of amalgam restorations pretreated with various liners. Am J Dent 1997;10:284-6.

102. Tobias RS, Browne RM, Plant CG, Ingram DV. Pulpal response to a glass ionômero cement. British Dental Journal 1978;11:345-350.

103. Trowbridge HO. Pulp histology and physiology. In: Cohen S, Burns RC. Patways of the pulp. St. Louis: Mosby; 1984.

104. Tyas MJ. Milestones in adhesion: glass-ionomer cements. J Adhes Dent. 2003 Winter;5(4):259-66.

105. Wasson EA, Nicholson JW. A study of the relationship between the setting chemistry and properties of modified glass polyalkenoate cements. Br Polym J 1990;23:179-183.

106. Wilson $A D$, Kent $B E$. The glass ionômero cement: a new translucent dental filling material. J Appl Chem Biotechnol 1971;21:313. 
107. Wilson AD, Prosser $H J$, Powis DM. Mechanism of adhesion of polyelectrolyte cements to hydroxyapatite. J Dent Res 1983;62:590-2.

108. Wisithphrom K, Murray PE, About I, Windson LJ. Interactions between cavity preparation and restoration events and their effects on pulp vitality. Int J Periodontics Restorative Dent 2006;26(6):596-605.

109. Xu X, Burgess JO. Compressive strength, fluoride release and recharge of fluoridereleasing materials. Biomaterials 2003 Jun;24(14):2451-61.

110. Yanikoğlu N, Yeşil Duymuş Z. Evaluation of the solubility of dental cements in artificial saliva of different pH values. Dent Mater J 2007 Jan;26(1):62-7.

111. Yoshida $Y$, Van Meerbeek B, Nakayama Y, Snauwaert J, Hellemans L, Lambrechts P, Vanherle G, Wakasa K. Evidence of chemical bonding at biomaterial-hard tissue interfaces. J Dent Res 2000;79:709-14.

112. Zach L, Cohen G. Thermogenesis in operative dentistry: comparison of four methods. J Prothet Dent 1962;12:977-84. 
Anexo 


\title{
Comitê DE Ética
}

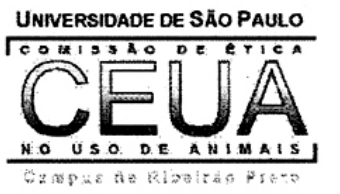

\author{
UNIVERSIDADE DE SÃO PAULO \\ Campus de Ribeirão Preto \\ Comissão de Ética no Uso de Animais
}

\section{E R T I F I C A D O}

Certificamos que o trabalho (Protocolo $n^{\circ}$ 05.1.1322.53.9), intitulado:

"Avaliação da Resposta Pulpar e Periapcal após Utilização de dois Agentes Cimentantes. Estudo histopatológico e radiográfico em dentes de cães", de autoria de Thais Helena Andreolli do Amaral, por estar de acordo com os Princípios Éticos na Experimentação Animal adotado pela Comissão de Ética no Uso de Animais (CEUA) do Campus de Ribeirão Preto - USP, foi aprovado em reunião da CEUA de 06.04.06

Ribeirão Preto, 12 de abril de 2006

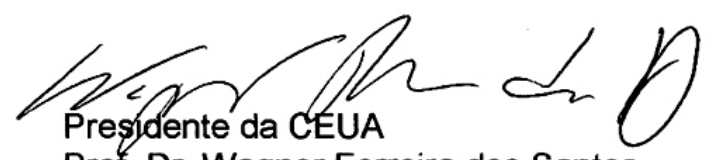

Prof. Dr. Wagner Ferreira dos Santos

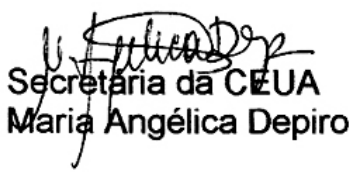




\section{AUTORIZAÇÃO PARA REPRODUÇÃO}

Autorizo a reprodução e/ou divulgação total ou parcial da presente obra, por qualquer meio convencional ou eletrônico, desde que citada a fonte.

Thais Helena Andreolli do Amaral Universidade de São Paulo Faculdade de Odontologia de Ribeirão Preto Departamento de Clínica Infantil, Odontologia Preventiva e Social

Ribeirão Preto/Julho de 2007

Avenida do Café s/n CEP 14040-904

e-mail: thaisandreolli@terra.com.br 